\title{
Impacts of land use and land cover change and reforestation on summer rainfall in the Yangtze River basin
}

\author{
Wei $\mathbf{L i}^{1,2}$, Lu Li ${ }^{3}$, Jie Chen ${ }^{1,2}$, Qian $\operatorname{Lin}^{1,2}$, and Hua Chen ${ }^{1,2}$ \\ ${ }^{1}$ State Key Laboratory of Water Resources and Hydropower Engineering Science, Wuhan University, Wuhan, 430072, China \\ ${ }^{2}$ Hubei Key Laboratory of Water System Science for Sponge City Construction, Wuhan University, Wuhan, 430072, China \\ ${ }^{3}$ NORCE Norwegian Research Centre, Bjerknes Centre for Climate Research, Jahnebakken 5, 5008, Bergen, Norway
}

Correspondence: Jie Chen (jiechen@whu.edu.cn)

Received: 27 August 2020 - Discussion started: 14 September 2020

Revised: 27 June 2021 - Accepted: 28 July 2021 - Published: 24 August 2021

\begin{abstract}
Land use and cover have been significantly changed all around the world during the last decade. In particular, the Grain for Green (GG) program has resulted in significant changes in regional land use and cover, especially in China. Land use and cover change (LULCC) may lead to changes in regional climate. In this study, we take the Yangtze River basin as a case study and analyze the impacts of LULCC and reforestation on summer rainfall amounts and extremes based on the Weather Research and Forecasting model. Firstly, two observed land use and cover scenarios (1990 and 2010) were chosen to investigate the impacts of LULCC on summer rainfall during the last decade. Secondly, two hypothetical reforestation scenarios (i.e., scenarios of $20 \%$ and $50 \%$ cropland changed to forest) were taken based on the control year of 2010 to test the sensitivity of summer rainfall (amounts and extremes) to reforestation. The results showed that average summer rainfall and extreme summer daily rainfall decreased in the Yangtze River basin between 1990 and 2010 due to LULCC. Reforestation could increase summer rainfall amount and extremes, and the effects were more pronounced in populated areas than over the whole basin. Moreover, the effects of reforestation were influenced by the reforestation proportion. In addition, the summer rainfall increased less conversely, with the transform proportion of cropland to forest increased from $20 \%$ to $50 \%$. By analyzing the changes in water vapor mixing ratio, upward moisture flux, and $10 \mathrm{~m}$ wind, it is suggested that this result might be caused by the horizontal transportation processes of moisture. Although a comprehensive assessment of the impacts of LULCC on summer rainfall amounts and extremes was
\end{abstract}

conducted, further studies are needed to investigate the uncertainty better.

\section{Introduction}

Human activities intensify land use and land cover change (LULCC) all around the world. With the human population increasing, more than one-third of global natural land uses have been altered by human activities during the past three centuries (Hurtt et al., 2006, 2011). The land surface is the lower boundary of atmospheric motion. Thus, LULCC can influence climate through various geophysical processes, such as the water and heat flux between the land surface and the atmosphere, surface wind speed, and boundary layer turbulence. LULCC can affect regional climate significantly, which is a broad consensus reached by many studies. For instance, Pitman et al. (2012) found that many of the temperature indices showed locally strong and statistically significant responses to LULCC, such as commonly $30 \%-50 \%$ of the continental surfaces of the tropics and Northern and Southern hemispheres being affected statistically significantly by LULCC. Wen et al. (2013) also found that land use changes in China could contribute to the warmest day temperature increases. Furthermore, Yu et al. (2020) found that the recent greening in China has resulted in a country-averaged surface cooling of $0.11^{\circ} \mathrm{C}$. Lin et al. (2020) showed that urbanization tended to result in weak extreme rainfall events in urban agglomerations over coastal regions and intensifies the influences on those in central and western China. 
China is experiencing significant land use changes due to human activities, especially in the high-population-density Yangtze River basin (YRB). The Yangtze River is the longest river in Asia and the third-longest globally, with a length of over $6300 \mathrm{~km}$. The YRB is the largest basin in China. It supports $34 \%$ of the national population and contributes $41.1 \%$ of China's gross domestic products (Zhang et al., 2014). Considering agricultural activities, urbanization, and dam construction, LULCC is quite significant in this basin (Liu et al., 2003; Zhang et al., 2009; Shen et al., 2019; Lin et al., 2021). Moreover, China launched the Grain for Green (GG) program to expand forestland in 1999, aiming to reduce soil erosion and alleviate poverty (Robbins and Harrell, 2014; Li et al., 2020). From 1999 to 2008, forest coverage, reported as a percentage of the country's total land area, increased from $16.55 \%$ to $20.36 \%$, adding $41.6 \times 10^{6}$ ha of forest (Trac et al., 2013). By 2013, China government had invested over RMB 320 billion in afforesting over $29 \times 10^{6}$ ha (Zinda et al., 2017). GG focused on increasing forest cover through cropland conversion and afforestation and reforestation of barren hillsides. Sloping cropland was a core target of the program, which was blamed for $65 \%$ of the 2 to $4 \times 10^{9} \mathrm{t}$ of silt released into the Yangtze and middle and upper reaches of the Yellow River each year (Bennett et al., 2011). Because of GG, there was also a trend of LULCC in the YRB of turning cropland into forest. All the LULCC in the YRB has changed the regional climate during the past few decades. For example, Cui et al. (2012) found that reforestation could increase evapotranspiration and decrease water yield at the forest stand level in the upper reach of the YRB. Liu et al. (2013) showed that reforestation in the upstream of the YRB increased annual evapotranspiration, leading to reductions in surface flow and baseflow. In addition, Hu et al. (2015) found that LULCC in eastern China caused a decrease in rainfall over the lower reaches of the YRB of approximately $3 \%$ in the summer from the 1980s to the 2000s. Zhang et al. (2017) showed that the temperature decreased by $0.2-0.4^{\circ} \mathrm{C}$ in the midstream and downstream of the YRB in spring, autumn, and winter, and seasonal rainfall also decreased from the 1980 s to the 2000s due to LULCC. Furthermore, Feng et al. (2018) showed that the land surface temperature over the Taihu Lake basin, which is located in the lower reaches of the YRB, has been increasing since 1996, caused by local urbanization.

The YRB plays a vital role in ecosystem protection and economic development for the whole country. However, the YRB has suffered from frequent flooding during the past decades. Summer rainfall from June to August is the leading cause of summer flooding in the YRB, which largely influences the lives of local people. Thus, it is crucial to better understand the impacts of LULCC on summer rainfall in the YRB, especially the effects of the GG reforestation program. Although many studies have estimated the impacts of LULCC on rainfall in the YRB, it should be noted that most of the previous studies only focused on the midstream and downstream of the YRB. Moreover, the sensitivity of summer rainfall to reforestation in the YRB was rarely investigated. And few previous studies discussed the potential physical mechanisms linked to the changes in summer rainfall under reforestation. Investigating the impacts of LULCC, especially reforestation, on rainfall, is of great importance for the economic and ecological development of the YRB, as well as for China. There is an urgent need considering the Yangtze River Coordinated Protection Strategy proposed by the Chinese government in 2016, aiming to prioritize ecology and green development, promote well-coordinated environmental conservation, and avoid excessive development.

Therefore, this study took the YRB as a case study and investigated the impact of LULCC and reforestation on summer rainfall and extreme hazards (from June to August). More specifically, two observed LULCC scenarios were chosen to study the impacts of observed LULCC on summer rainfall, including both amounts and extremes, while two hypothetical reforestation scenarios were taken to quantitatively assess the impacts of reforestation on summer rainfall (amount and extremes) under different reforestation proportions. The differences in summer rainfall between the four land use scenarios (two observed and two hypothetical ones) were applied and investigated based on the Weather Research and Forecasting (WRF) model. The major objectives of this study were to (1) estimate the impacts of LULCC and reforestation on summer rainfall (amount and extremes) in the YRB and (2) investigate how the proportion of reforestation affects summer rainfall (amount and extremes) in the YRB.

To better understand the impacts of LULCC and reforestation on summer rainfall, the performance of WRF-simulated rainfall was first evaluated in Sect. 4.1. Then, the changes in summer rainfall between the 1990 scenario and 2010 scenario were analyzed to investigate the impacts of observed LULCC on summer rainfall in Sect. 4.2. In Sects. 4.3.1 and 4.3.2, the impacts of reforestation on summer rainfall were analyzed based on the spatial changes and area average changes, respectively. Moreover, in Sects. 4.3.3 and 4.3.4, the impacts of reforestation on some other climate variables related to the rainfall were also investigated. These climate variables contained the latent heat flux (LHF), sensible heat flux (SHF), planetary boundary layer height (PBLH), $2 \mathrm{~m}$ air temperature, $2 \mathrm{~m}$ relative humidity, and $2 \mathrm{~m}$ water vapor mixing ratio. The analyses of these variables aimed to explain the potential mechanisms of the changes in summer rainfall under reforestation. The discussions and conclusions are given at the end. Our results will contribute to a better understanding of regional climate characteristics (summer rainfall and extremes) under the impacts of LULCC and the reforestation program in the YRB and provide a knowledge base for ecological reconstruction programs in the future. 


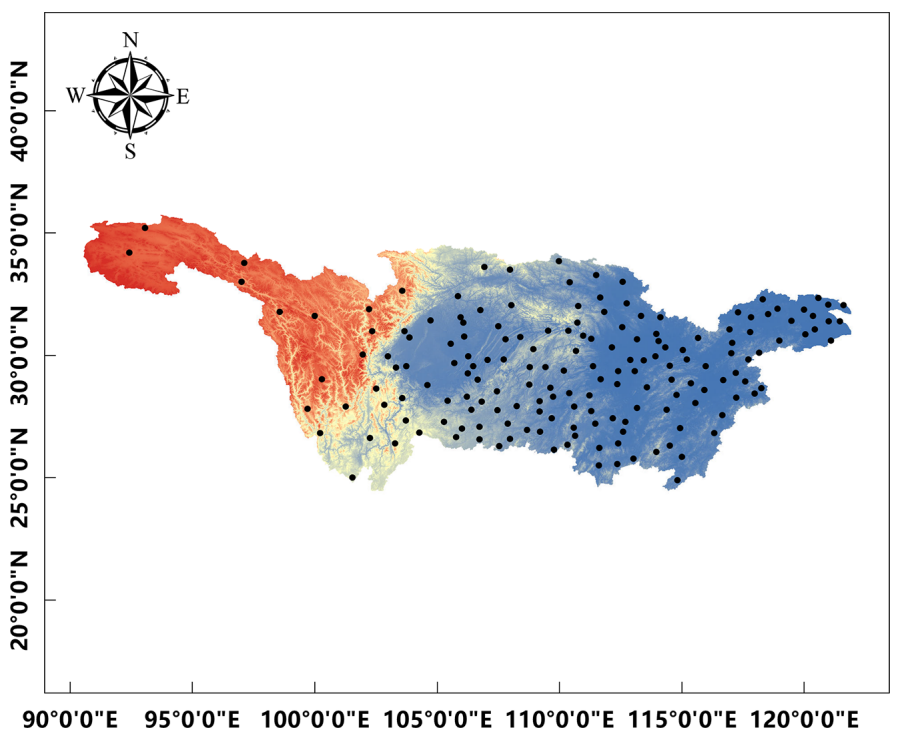

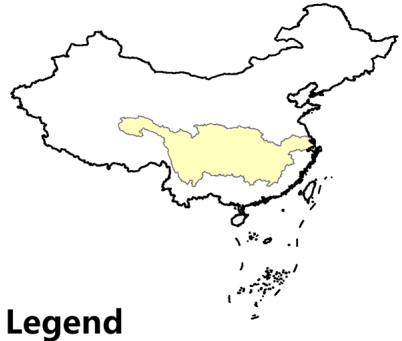

- Climate observation station

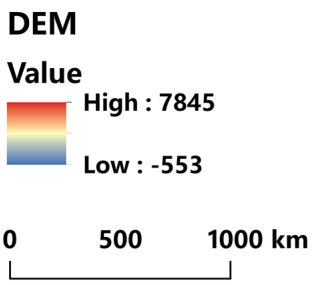

Figure 1. The location and topography of the Yangtze River basin and the location of climate observation stations.

\section{Study area and data}

\subsection{Study area}

This study focuses on the YRB (Fig. 1), which has a total area of $\sim 1.8 \times 10^{6} \mathrm{~km}^{2}$ (Wang et al., 2018). The YRB is located between $24-35^{\circ} \mathrm{N}$ and $90-122^{\circ} \mathrm{E}$, spanning from the eastern Tibetan Plateau to the East China Sea and crossing 19 provinces in China. The upper, middle, and lower reaches of the YRB cover $1.0 \times 10^{6} \mathrm{~km}^{2}, 6.8 \times 10^{5} \mathrm{~km}^{2}$, and $1.2 \times 10^{5} \mathrm{~km}^{2}$, respectively (Zhang et al., 2014). LULCC in the YRB has been quite significant during the past few decades. The main types of LULCC include urbanization, which leads to the conversion of cropland to urban areas in the middle and lower reaches (Liu et al., 2010, 2012; Gao et al., 2012), degradation of grassland caused by overgrazing in the headwater region (Gao et al., 2009, 2010), and reforestation and afforestation, as a result of the implementation of GG (Liu et al., 2010; Li et al., 2014). The upper reaches of the YRB belong to a high-cold climate zone, whereas the middle and lower reaches belong to subtropical and temperate climate zones (D. Zhang et al., 2019). The whole YRB is sensitive and vulnerable to climate change (Fang et al., 2010). The average air temperature ranges from 9 to $18^{\circ} \mathrm{C}$, and the average annual rainfall ranges from 692 to $1611 \mathrm{~mm}$ (D. Zhang et al., 2019). The flash flooding in the Yangtze River basin is often caused by continuous rainfall that lasts for a few days, as it is a large basin (Chen et al., 2020; Nanding et al., 2020). A few hours of high-intensity rainfall do not cause severe flooding due to cascade reservoirs' construction along the river. Because of relatively good water and temperature conditions, vegetation productivity is generally high in this area. However, human activities are intensifying LULCC in the YRB from the upper reaches to the lower reaches (Sun et al., 2016), which will gradually change the local climate and influence agriculture production.

\subsection{Data}

This study used WRF simulations to investigate the impacts of LULCC on summer rainfall. The WRF model with the Advanced Research WRF dynamics solver version 3.9.1 was used (Skamarock et al., 2008). The WRF model is a flexible, state-of-the-art, non-hydrostatic, mesoscale numerical weather prediction, and atmospheric simulation system (Wagner et al., 2016). The lateral boundaries of the WRF model were forced with the $0.5^{\circ}$ ERA Interim reanalysis (Berrisford et al., 2011). The output interval of the WRF model was $1 \mathrm{~d}$. The output variables of the WRF model that included rainfall, LHF, SHF, PBLH, $2 \mathrm{~m}$ air temperature, $2 \mathrm{~m}$ relative humidity, and $2 \mathrm{~m}$ water vapor mixing ratio were used in this study to analyze the changes in rainfall under LULCC and the potential physical mechanisms.

In addition, the observed rainfall and temperature from 171 stations in the YRB were used for model validation (Fig. 1). The observed data were quality-controlled and provided by the China Meteorological Data Sharing Service System. In our study, the observed data from stations were interpolated to model grids by the inverse distance weighting (IDW) interpolation method. Meanwhile, to better validate the model performance, the ERA5 data were used as the benchmark to validate some thermodynamics variables as we did not have gauged observations for these variables. The spatial resolution of ERA5 data is $0.25^{\circ}$. In this study, the ERA5 data were interpolated to model grids using the bilinear interpolation method. Moreover, to better understand the impacts of LULCC and reforestation on human lives, the 2010 Grid Population Dataset of China developed by Fu 

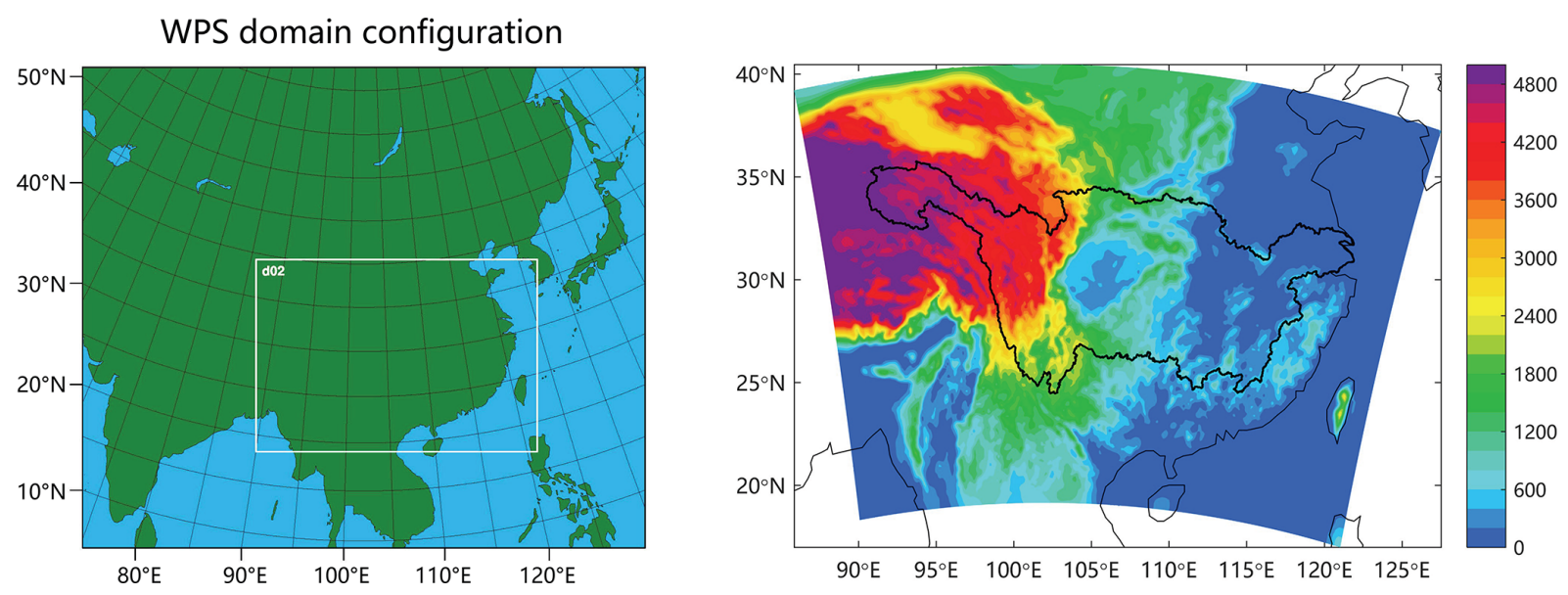

Figure 2. The WRF model domain and the model topography (units: m).

et al. (2014) was used. This dataset was developed based on remote-sensing-derived land use types and statistical population data. The spatial resolution of this dataset is $1 \mathrm{~km}$. This dataset was also interpolated to model grids using the IDW method.

In addition, the 1990 and 2010 land use data of the YRB were derived from the Landsat Thematic Mapper (TM) digital images (http://www.dsac.cn/ServiceCase/Detail/174574, last access: 27 July 2021). It was interpreted based on the geometric shape, texture features, spatial distribution of the ground objects, and the spectral characteristics of images. Moreover, an outdoor survey and random sample check were also taken to enhance the accuracy of land use data. The land use changes were included in the WRF modeling by modifying the static geographical data, which further changed the simulation of subprocesses such as the vegetation phenology, canopy stomatal resistance, runoff, and groundwater in the land surface model Noah-MP (Li et al., 2018). Many parameters were used in Noah-MP to describe the characteristics of different land use types, such as albedo, TOC (top of canopy), LAI (monthly leaf area index), and VCMX25 (maximum rate of carboxylation at $25^{\circ} \mathrm{C}$ ). When the land use changed, these parameters changed accordingly, which finally led to the changes in substance and energy exchanges between the atmosphere and land surface. In the study, we used the U.S. Geological Survey (USGS) land cover with $30 \mathrm{~s}$ resolution $(\sim 1 \mathrm{~km}$ resolution; "landuse_30 s_with_lakes") in the WRF Preprocessing System (WPS). The new land use data of 1990 and 2010 derived from the Landsat TM digital images at $1 \mathrm{~km}$ resolution were then used to replace the USGS land cover data in the WRF simulation in YRB. As the resolutions of the outer and inner WRF domain were set to 75 and $15 \mathrm{~km}$, respectively, the post-processed land use data were resampled from 1 to $75 \mathrm{~km}$ and $15 \mathrm{~km}$ using the WPS. The dominant land use categories in model grids were then used for the Noah-MP model to reflect the intended land use changes correctly. The land use categories of the 1990 and 2010 land use data from Landsat TM digital images were defined by Liu et al. (2002, 2005), which are commonly used in China; while the USGS data for WRF modeling have 24 land use categories (including lake). Thus, we used the method of land use type conversions based on the study of Hu et al. (2015). According to this method, the four classes of land use in Liu's categories from Landsat TM digital images, including the forest (Liu code 21), shrub (Liu code 22), sparse woodland (Liu code 23), and cutover land (Liu code 24), were converted to four classes of USGS land use category, including deciduous broadleaf forest (USGS code 11), shrubland (USGS code 8), savanna (USGS code 10), and savanna (USGS code 10), respectively.

\section{Methods}

\subsection{WRF model configuration}

The WRF model was set up with two nested domains in this study (Fig. 2). The resolutions of the outer and inner domain were $75 \mathrm{~km}(95 \times 82$ grids $)$ and $15 \mathrm{~km}(236 \times 161$ grids $)$, respectively. The model was set up with 32 vertical levels, and the top was at $50 \mathrm{hPa}$ in all domains. The simulated period was 11 years from 2000 to 2010 , with the first year taken as spin-up time. The initial and lateral boundary conditions were taken from the $0.5^{\circ}$ ERA Interim reanalysis dataset. The time step was $90 \mathrm{~s}$ in both domains.

The choices of the microphysical scheme and cumulus parameterization are important for rainfall simulations $(\mathrm{Li}$ et al., 2017). According to previous studies in China (Hu et al., 2015; H. Zhang et al., 2019; Feng et al., 2012; Xue et al., 2017), three microphysical schemes, i.e., the Purdue Lin Scheme (Lin) (Chen and Sun, 2002), the WRF single-moment class 5 scheme (WSM5) (Hong et al., 2004), and the Eta (Ferrier) scheme (Ferrier) (Maw et al., 2017), and two cumulus parameterizations, i.e., the Kain-Fritsch scheme (KFN) (Kain, 2004) and the Grell-Devenyi ensem- 
ble scheme (GD) (Grell and Dévényi, 2002), were chosen to validate the WRF model. Five parameterization scheme combinations (i.e., Lin-KFN, WSM5-KFN, Ferrier-KFN, Lin-GD, and WSM5-GD) were then used to simulate the rainfall and temperature in the YRB during the summer of 2005 (from June to August), as there were several rainstorm events in summer 2005 in this basin. The most suitable parameterization schemes were chosen by comparing the performance of these five combinations in simulating these rainstorm events. The domain setting was the same as the whole experiment which can be seen in Fig. 2. Finally, the Lin and GD schemes were set as the microphysical scheme and cumulus parameterization, respectively.

In addition, the Yonsei University scheme was used for the planetary boundary layer (Hong et al., 2006); the Dudhia scheme for shortwave radiation (Dudhia, 1988); the RRTM scheme for longwave radiation (Mlawer et al., 1997), and the Noah-MP scheme for the land surface model (Niu et al., 2011; Yang et al., 2011).

\subsection{The observed land use scenarios and hypothetical reforestation scenarios}

The 1990 and 2010 land use scenarios were chosen to estimate the impacts of observed LULCC on summer rainfall amount and extremes in this study (Fig. 3a and b). From 1990 to 2010, the YRB suffered significant LULCC. In this period, the main LULCC in the YRB was urbanization and reforestation and the constructions of dams (Liu et al., 2003; Zhang et al., 2009; Shen et al., 2019). Furthermore, to investigate the impacts of reforestation due to GG, we randomly changed $20 \%$ and $50 \%$ of the cropland to forest based on the observed land use scenario of 2010 (Fig. 3c and d). These two reforestation scenarios were independently produced using random sampling and can be considered as two extreme cases in the progress of GG for the future. The hypothetical reforestation scenarios (denoted the $20 \%$ scenario and the $50 \%$ scenario) were used in the study as well as the observed land use in 1990 and 2010 (denoted the 1990 scenario and the 2010 scenario). When we changed croplands to forests, the proportions of each type of croplands (forests) occupied in total croplands (forests) were kept fixed. Moreover, Table 1 displays the percentages of land use classes under four scenarios, while Table S1 in the Supplement displays the percentages of land cover under four scenarios after being resampled to $15 \mathrm{~km}$.

\section{Results}

\subsection{WRF model validation}

Figure 4 displays the spatial distributions of biases in the average summer rainfall and extreme summer daily rainfall (the 90th and 99th percentile of summer daily rainfall) simulated by WRF relative to observation and the q-q plot of observed rainfall versus simulated rainfall. From Fig. 4a, it can be seen that the biases of WRF-simulated average summer rainfall range from $-120 \%$ to $200 \%$. The positive biases are mainly observed in the transaction region between the Sichuan Basin and the Tibetan Plateau, with the maximum positive biases in the front zone of the Tibetan Plateau where the altitudes shift from low to high rapidly. The negative biases are mainly observed in the southeastern YRB, which were also found in other studies (Zhang et al., 2017). Figure 4b and c present the biases of the 90th and 99th percentiles of summer daily rainfall simulated by WRF relative to observations, respectively. The 90th and 99th percentiles are average values over 10 years. The biases of the 90th and 99th percentiles of summer daily rainfall have almost identical spatial distributions and vary from $-80 \%$ to $200 \%$. The positive biases are mainly observed in the upstream area where the altitudes are higher than $1200 \mathrm{~m}$, while the negative biases are mainly observed in the midstream and downstream areas, with the maximum negative biases located in the southeastern YRB. The q-q plot of observed basin-averaged rainfall versus simulated basin-averaged rainfall in Fig. $4 d$ shows that the distribution of basin-averaged rainfall simulated by WRF is linearly correlated with that of observation.

Figure 5a presents the basin-averaged summer rainfall processes (from June to August) of observed, ERA5, and WRF-simulated rainfall (2010 scenario). The summer rainfall processes are the multiyear-averaged results of 10-year data from 2001 to 2010. It can be seen that ERA5 rainfall is overestimated compared with the observed rainfall. The rainfall simulated by WRF falls within the spread between the observation and ERA5 rainfall at the beginning of summer and then becomes smaller than the observation. Figure $5 \mathrm{~b}$ presents the probability distribution functions (PDFs) of observed, ERA5, and WRF-simulated summer rainfall. The PDF of WRF-simulated rainfall is larger than that of the observation when rainfall is less than $3 \mathrm{mmd}^{-1}$. The PDF of ERA5 rainfall is larger than that of the observation when rainfall is greater than $5 \mathrm{mmd}^{-1}$. In general, the PDF of WRF-simulated rainfall is more similar to that of observation than that of ERA5.

The spatial distribution of biases in average summer temperature simulated by WRF relative to the observation is presented in Fig. 6a. The results show that temperature simulated by WRF tends to be lower than the observation, mainly in the upstream of the YRB. In most places of the YRB, the biases of temperature simulated by WRF range from $-10 \%$ to $10 \%$. The q-q plot of observed basin-averaged temperature versus simulated basin-averaged temperature in Fig. 6b shows that the distribution of basin-averaged temperature simulated by WRF is linearly correlated with that of observation. Figure $6 \mathrm{c}$ presents the basin-averaged summer temperature processes of the observation and ERA5 and WRF simulations. The summer temperature process simulated by WRF always falls within the spread between the observation and ERA5 data from June to August. However, systematic bi- 

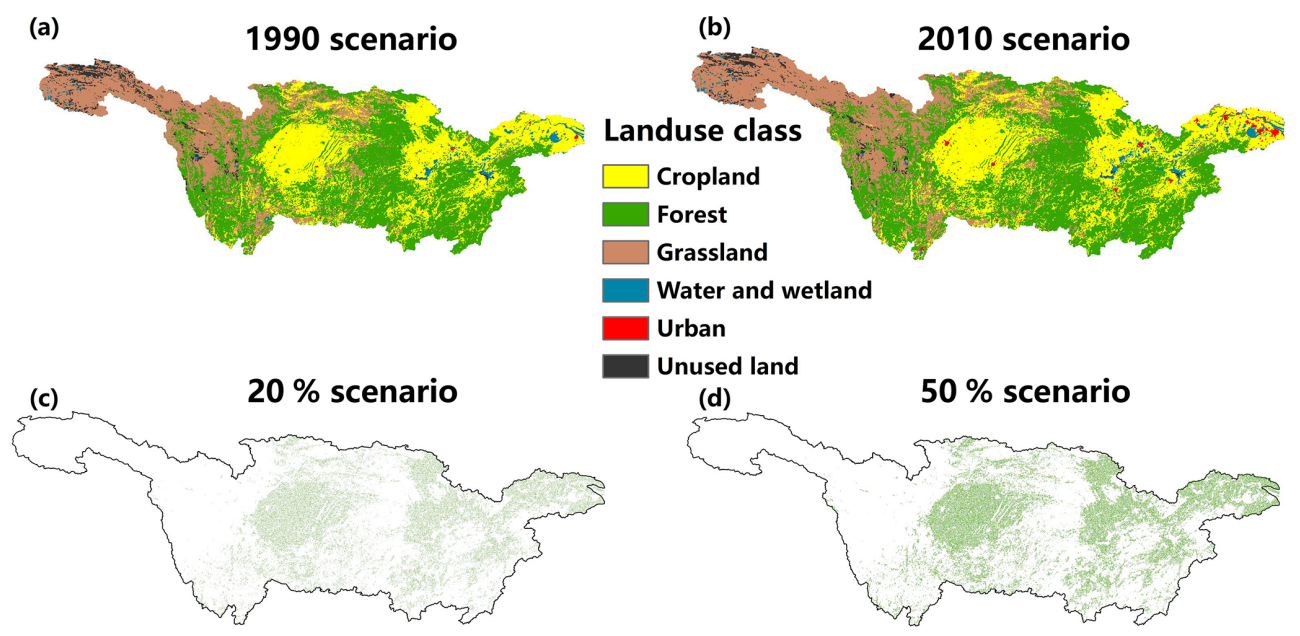

Figure 3. (a, b) Land use and cover under 1990 and 2010 scenarios. (c, d) Land use and cover changes between the two hypothesis scenarios (20\% and $50 \%$ scenarios) and 2010 scenario.

Table 1. The percentages of land use classes under four scenarios.

\begin{tabular}{lrrrrrr}
\hline Scenarios & Cropland (\%) & Forest $(\%)$ & Grassland $(\%)$ & Water and wetland $(\%)$ & Urban (\%) & Unused land (\%) \\
\hline 1990 scenario & 29.15 & 42.82 & 23.50 & 1.65 & 0.19 & 2.69 \\
2010 scenario & 28.48 & 43.60 & 23.13 & 1.79 & 0.86 & 2.14 \\
$20 \%$ scenario & 22.80 & 49.28 & 23.13 & 1.79 & 0.86 & 2.14 \\
$50 \%$ scenario & 14.58 & 57.50 & 23.13 & 1.79 & 0.86 & 2.14 \\
\hline
\end{tabular}

ases are observed for temperature. Similar results have also been found in other studies. For example, Zhang et al. (2017) found that there was a cold temperature bias in eastern China when simulated by the WRF model, and the bias was up to $5^{\circ} \mathrm{C}$ in some regions. Yan et al. (2021) also showed that the WRF model produced a large cold bias over the whole of China, with the exception of northwestern Xinjiang.

To better validate the model performance, biases of the LHF, SHF, and PBLH simulated by WRF are further analyzed using ERA5 as the benchmark since no such observations are available in the study. Figure S1 in the Supplement presents the spatial distributions of biases in the LHF, SHF, and PBLH simulated by WRF relative to ERA5. The LHF simulated by WRF is lower than ERA5 for most places of the YRB. The most significant biases are mainly observed in the upstream of the YRB (Fig. S1a). For most places of the YRB, biases of LHF range from $-40 \%$ to 0 . For the SHF (Fig. S1b), the negative biases are mainly observed in the upstream of the YRB, while the positive biases are mainly observed in the east of the YRB. For the PBLH (Fig. S1c), the positive biases are mainly observed in the upstream of the YRB, ranging from $20 \%$ to $100 \%$. The negative biases are mainly observed in the midstream and downstream of the YRB, ranging from $-80 \%$ to $-20 \%$. For most places of the YRB, biases of PBLH range from $-20 \%$ to $20 \%$. Although the absolute percent biases of these three variables between simulated data and ERA5 data are larger than $20 \%$ in some places of the YRB, it does not mean that the model is not properly configured, as biases exist between observed data and ERA5 data, and sometimes the biases are large (Gleixner et al., 2020; Tarek et al., 2020). For example, Al-Falahi et al. (2020) showed that the percent bias of average annual precipitation of ERA5 and ground stations was $-88.97 \%$ over the Al Mahwit governorate in Yemen. Moreover, the simulated data are closer to the observation than the ERA5 data for the rainfall and temperature.

\subsection{The impacts of LULCC between the 2010 and 1990 scenarios on summer rainfall}

Figure 7 shows the differences in the average summer rainfall and extreme summer daily rainfall in YRB between the 2010 and 1990 scenarios. According to the results, the average summer rainfall differences vary from -200 to $200 \mathrm{~mm}$ over the YRB (Fig. 7a). In most places of the YRB, the average summer rainfall decreases for the 2010 scenario compared with the 1990 scenario. The increases in average summer rainfall are mainly observed in the upstream and midstream. Compared with the average summer rainfall, the changes in 90th percentile summer daily rainfall between the 1990 and 2010 scenarios show a similar spatial distribution (Fig. 7b), while the 99th percentile show a slightly different spatial distribution between two scenarios (Fig. 7c). For example, the 
(a) Average summer rainfall (\%)

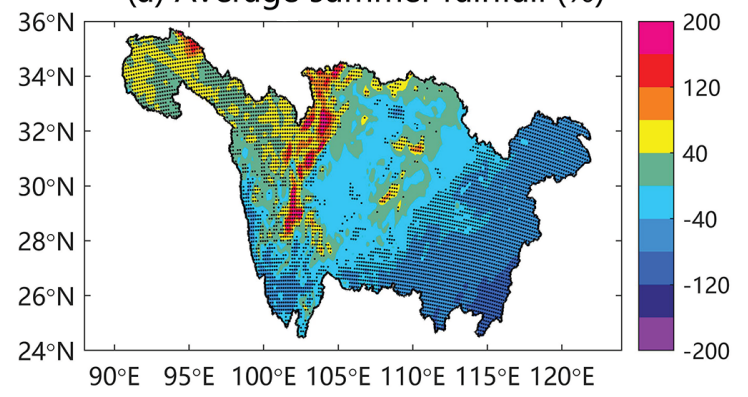

(c) 99 th percentile summer rainfall (\%)

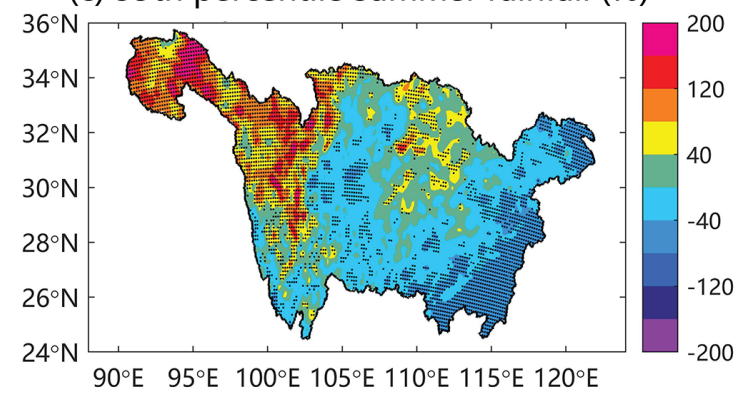

(b) 90th percentile summer rainfall (\%)

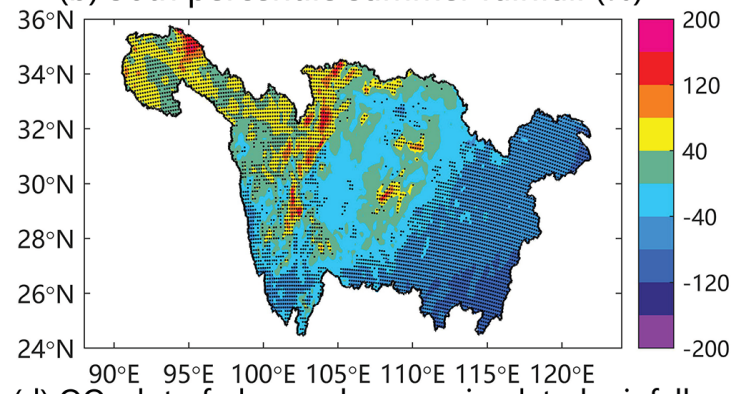

(d) QQ-plot of observed versus simulated rainfall

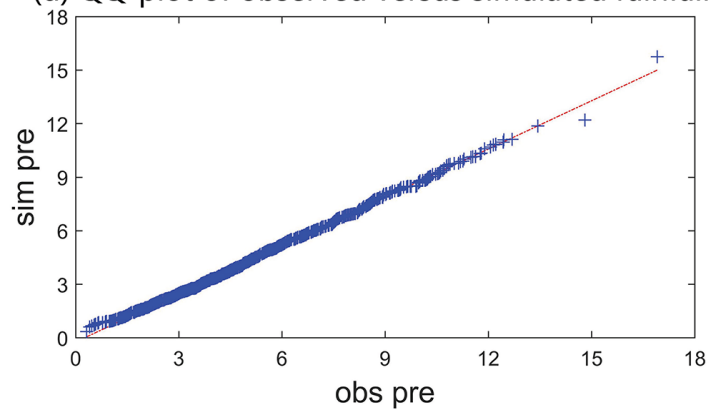

Figure 4. The bias of (a) average summer rainfall (\%), (b) 90th percentile summer rainfall (\%), and (c) 99th percentile summer rainfall (\%) between the 2010 scenario and observed data and (d) the q-q plot of observed rainfall versus simulated rainfall. The stippled regions show statistical significance of the bias identified by the $t$ test at a $5 \%$ significance level.

(a) Summer rainfall process

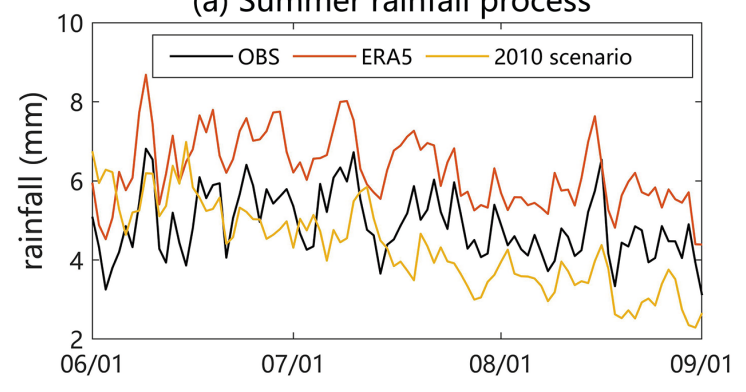

(b) The PDF of summer rainfall

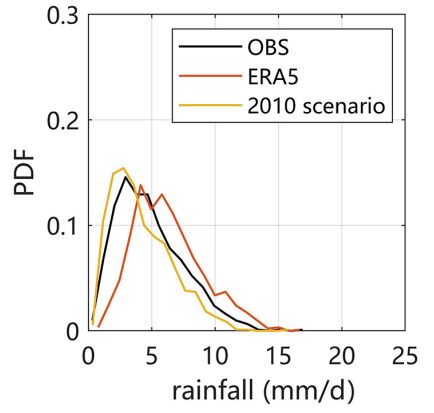

Figure 5. (a) The basin-averaged summer rainfall processes of the observation, ERA5, and the 2010 scenario. (b) The probability distribution functions of summer rainfall of the observation and ERA5 and 2010 scenarios.

90th percentile summer daily rainfall increases up to $10 \mathrm{~mm}$, mainly observed in the upstream and midstream, while the 99th percentile summer daily rainfall increases up to $50 \mathrm{~mm}$, mainly observed in the midstream and downstream. In addition, the changes in 99th percentile summer daily rainfall are more significant than those in 90th percentile summer daily rainfall.

Furthermore, changes in rainfall between the 2010 and 1990 scenarios are analyzed based on two types of area average: one is the area average based on all grids of the whole YRB (ALL-YRB), and the other is based on only the grids where the population density is greater than 100 per $\mathrm{km}^{2}$ (PDG-YRB). There are 3625 grids of the PDG-YRB out of 7935 grids of the whole YRB. The spatial distributions of grids of the PDG-YRB are displayed in Fig. 8. Figure S2 in the Supplement presents the changes in average summer rainfall and extreme summer daily rainfall between the 2010 and 1990 scenarios for ALL-YRB and PDG-YRB. Similarly, Fig. S3 in the Supplement presents the changes in maximum 1,3 , and $5 \mathrm{~d}$ summer rainfall between the 2010 and 1990 scenarios. The results show that for most of the years, the rainfall statistics decrease from the 2010 scenario to the 1990 scenario. Moreover, the variation ranges of all statistics are always larger for PDG-YRB than for ALL-YRB.

To further understand the responses and sensitivities of summer rainfall to the impacts of LULCC, PDFs of average summer rainfall are shown in Fig. S4a and b in the Supplement for 1990 and 2010 scenarios, respectively. In general, 

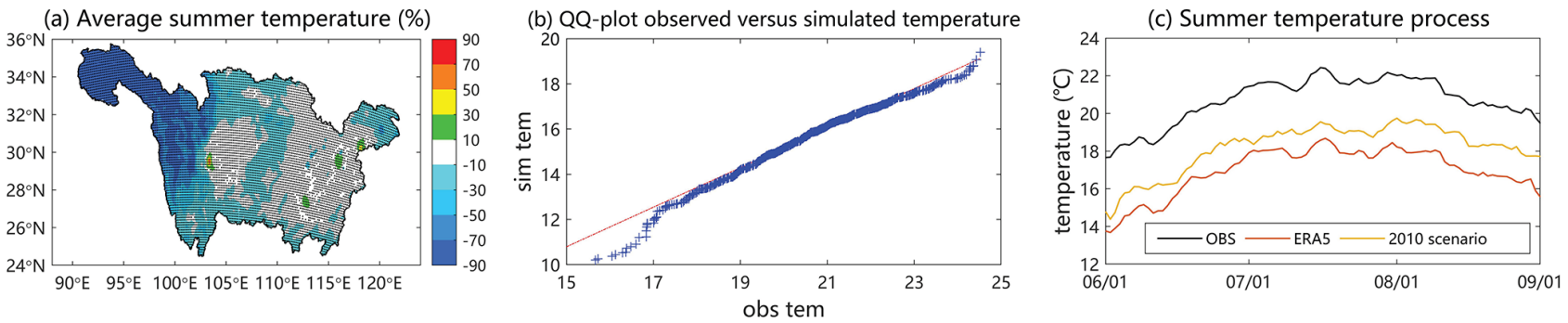

Figure 6. (a) The biases of average summer temperature (\%) between the 2010 scenario and observed data; the stippled regions show statistically significance of bias identified by $t$ test at a $5 \%$ significance level. (b) The q-q plot of observed temperature versus simulated temperature. (c) The basin-averaged summer temperature processes of the observation, ERA5, and the 2010 scenario.

(a) Average summer rainfall $(\mathrm{mm})$

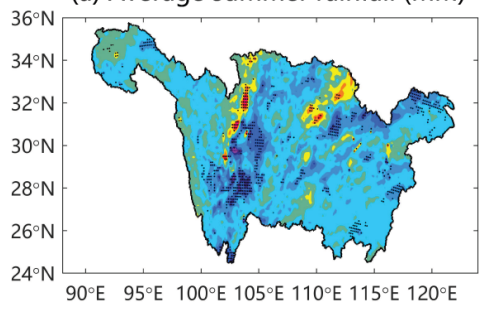

(b) 90 th percentile summer rainfall $(\mathrm{mm} / \mathrm{d})$
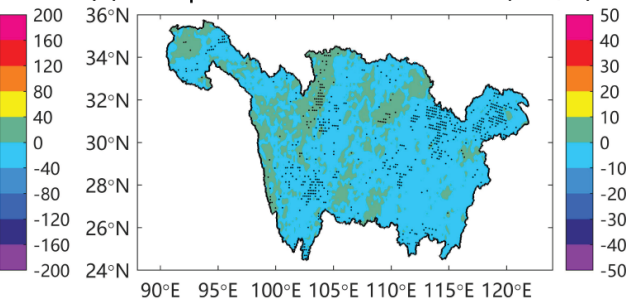

(c) 99th percentile summer rainfall $(\mathrm{mm} / \mathrm{d})$

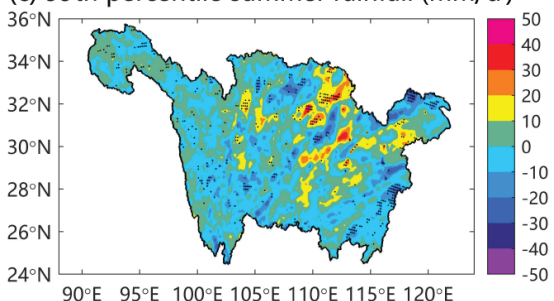

Figure 7. The changes in (a) average summer rainfall (mm), (b) 90 th percentile summer rainfall $\left(\mathrm{mm} \mathrm{d}^{-1}\right.$ ), and (c) 99 th percentile summer rainfall $\left(\mathrm{mm} \mathrm{d}^{-1}\right)$ between the 2010 scenario and 1990 scenario. The stippled regions show statistical significance of the changes identified by the $t$ test at a $5 \%$ significance level.

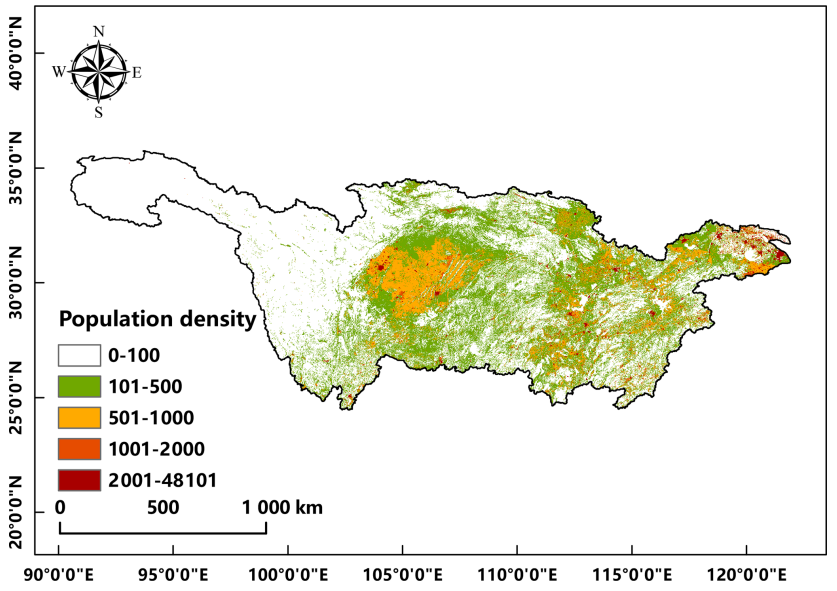

Figure 8. The spatial distributions of grids where the population density is greater than 100 per $\mathrm{km}^{2}$ (PDG-YRB).

the PDF of the 2010 scenario is higher than that of the 1990 scenario for both ALL-YRB and PDG-YRB. Moreover, the PDF of the same scenario (1990 or 2010 scenario) is higher for PDG-YRB than for ALL-YRB. Figure S4c and d present the relative changes in multiyear-averaged monthly rainfall during the summer period between the 2010 and 1990 scenarios for both ALL-YRB and PDG-YRB. It can be found that the summer rainfall for the 2010 scenario decreases compared with the 1990 scenario as the relative changes from June to August are all negative.

\subsection{The impacts of reforestation on the regional climate in the YRB}

\subsubsection{Changes in summer rainfall}

Figure $9 \mathrm{a}$ and $\mathrm{b}$ show the spatial changes in the average summer rainfall between the $20 \%$ scenario and the 2010 scenario and between the $50 \%$ scenario and the 2010 scenario, respectively. From the results, we can see that the average summer rainfall shows a large spatial heterogeneity over the study area. For the $20 \%$ scenario, the increases of average summer rainfall (up to $200 \mathrm{~mm}$ ) are observed in most places of the YRB, while the decreases (up to $-100 \mathrm{~mm}$ ) are mainly observed in the upstream region. For the $50 \%$ scenario, the most significant increase in average summer rainfall is observed in the upstream of the YRB, while the most significant decrease is observed in the midstream region. When comparing the changes in average summer rainfall between the $20 \%$ and $50 \%$ scenarios, areas with an increase in average summer rainfall are more expansive for the $20 \%$ scenario than for the $50 \%$ scenario.

The spatial distributions of the changes in the 90th percentile summer daily rainfall (Fig. 9c and d) are similar to those in average summer rainfall for both the $20 \%$ and $50 \%$ scenario. The changes in 90th percentile summer daily rainfall range from -10 to $10 \mathrm{~mm}$. Figure $9 \mathrm{e}$ and $\mathrm{f}$ show the changes in the 99 th percentile summer daily rainfall between the $20 \%$ scenario and the 2010 scenario and between the $50 \%$ scenario and the 2010 scenario, respectively. For the 
(a) Average summer rainfall ( $\mathrm{mm}$ )

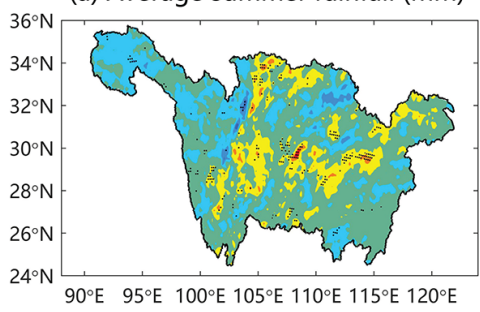

(b) Average summer rainfall $(\mathrm{mm})$

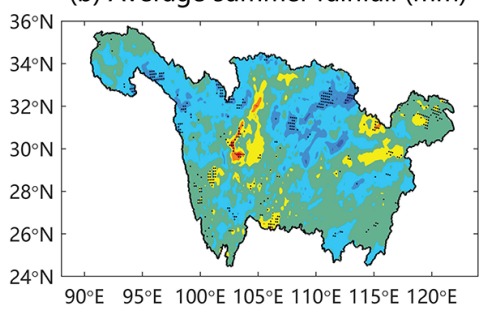

$20 \%$ scenario (c) 90th percentile summer rainfall $(\mathrm{mm} / \mathrm{d})$
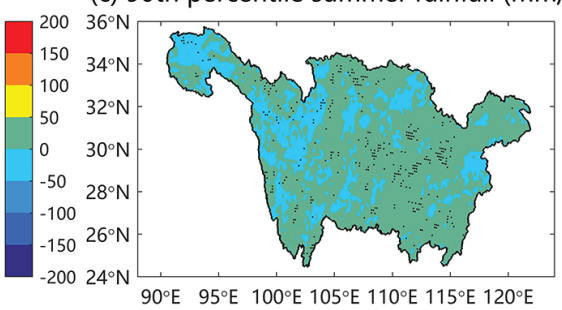

$50 \%$ scenario

(d) 90 th percentile summer rainfall $(\mathrm{mm} / \mathrm{d})$

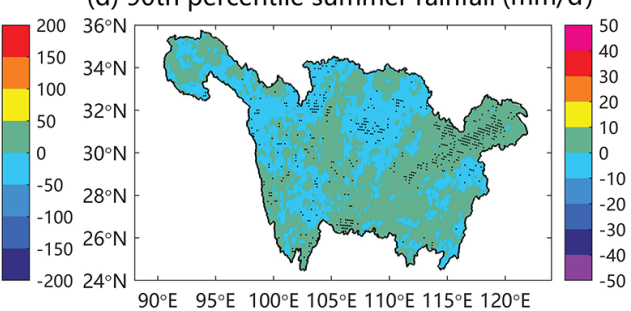

(e) 99th percentile summer rainfall $(\mathrm{mm} / \mathrm{d})$

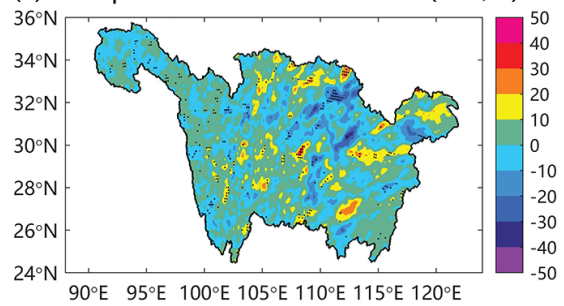

(f) 99 th percentile summer rainfall $(\mathrm{mm} / \mathrm{d})$

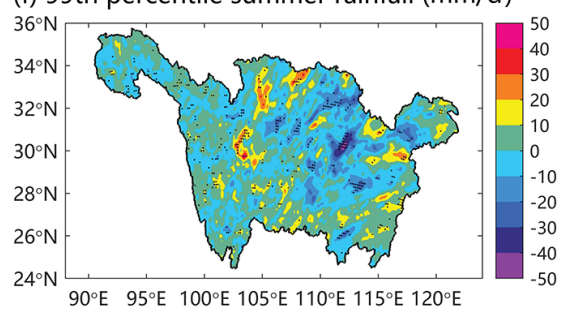

Figure 9. The changes in (a, b) average summer rainfall $(\mathrm{mm}),(\mathbf{c}, \mathbf{d}) 90$ th percentile summer rainfall $\left(\mathrm{mmd}^{-1}\right)$, and $(\mathbf{e}, \mathbf{f}) 99$ th percentile summer rainfall $\left(\mathrm{mmd}^{-1}\right)$ between the $20 \%$ scenario and the 2010 scenario and between the $50 \%$ scenario and the 2010 scenario. The stippled regions show statistical significance of the changes identified by the $t$ test at a $5 \%$ significance level.

$20 \%$ scenario, the 99th percentile summer daily rainfall increases in most places of the YRB, while the decreases are mainly observed in the midstream. For the $50 \%$ scenario, the most significant increase in the 99th percentile summer daily rainfall (up to $50 \mathrm{~mm}$ ) is mainly observed in the upstream of the YRB, while the most significant decrease (up to $-50 \mathrm{~mm}$ ) is mainly observed in the midstream. In addition, the decrease of the 99th percentile summer daily rainfall for the $50 \%$ scenario (up to $-50 \mathrm{~mm}$ ) is more significant than that for the $20 \%$ scenario (up to $-40 \mathrm{~mm}$ ). The above results indicate that the average summer rainfall and extreme summer daily rainfall are sensitive to reforestation (conversion from cropland to forest).

\subsubsection{Area average changes in rainfall}

Figure 10 presents the changes in average summer rainfall and extreme summer daily rainfall between the two hypothetical reforestation scenarios and the 2010 scenario for ALLYRB and PDG-YRB. For most of the years, the average summer rainfall increases for both hypothetical reforestation scenarios compared with the 2010 scenario. The mean values of changes in extreme summer daily rainfall among 10 years also show that all the extreme indices increase for both hypothetical reforestation scenarios compared with the 2010 scenario. The median values of the changes in all indices are more significant for the $20 \%$ scenario than for the $50 \%$ scenario for both ALL-YRB and PDG-YRB. Furthermore, the variation ranges of average and extreme summer daily rainfall are always larger for PDG-YRB than for ALL-YRB. In other words, the impacts of reforestation are more significant in populated areas.
Figure 11 presents the changes in maximum 1,3 and $5 \mathrm{~d}$ summer rainfall between the two hypothetical reforestation scenarios and the 2010 scenario. For the maximum $1 \mathrm{~d}$ rainfall, the median values of the $20 \%$ scenarios are positive, while those of the $50 \%$ scenario are negative. The maximum 3 and $5 \mathrm{~d}$ summer rainfall increase for most of the years for both hypothetical reforestation scenarios compared with the 2010 scenario. Moreover, the median values of the changes in all indices are larger for the $20 \%$ scenario than for the $50 \%$ scenario for both ALL-YRB and PDG-YRB. In addition, the impacts of reforestation are also more significant in populated areas than over the whole basin.

To indicate more clearly the responses and sensitivities of summer rainfall to the impacts of reforestation, the PDFs of average summer rainfall for the three scenarios (i.e., 2010, $20 \%$, and $50 \%$ scenarios) are shown in Fig. 12a and b. Figure 12a presents the PDFs of average summer rainfall for the three scenarios for ALL-YRB. The PDFs of rainfall for the three scenarios are pretty similarly averaged for ALL-YRB, except for the light rainfall of $2 \sim 4 \mathrm{~mm} \mathrm{~d}^{-1}$, which is more for the 2010 scenario than for the $20 \%$ scenario and $50 \%$ scenario. Figure $12 \mathrm{~b}$ presents the PDFs of average summer rainfall for three scenarios for PDG-YRB. The PDF of rainfall for the 2010 scenario is higher than that for the $20 \%$ and $50 \%$ scenarios when rainfall is less than $4 \mathrm{mmd}^{-1}$. The PDF for the $20 \%$ scenario is higher than that for the $50 \%$ scenario when rainfall is about $2-4 \mathrm{~mm} \mathrm{~d}^{-1}$. Moreover, the PDF for the $20 \%$ scenario is higher than that for the 2010 scenario when rainfall is around $5.5-7.5 \mathrm{~mm} \mathrm{~d}^{-1}$. Figure $12 \mathrm{c}$ and $\mathrm{d}$ present the relative changes in multiyear-averaged monthly rainfall during the summer period between the two hypothet- 

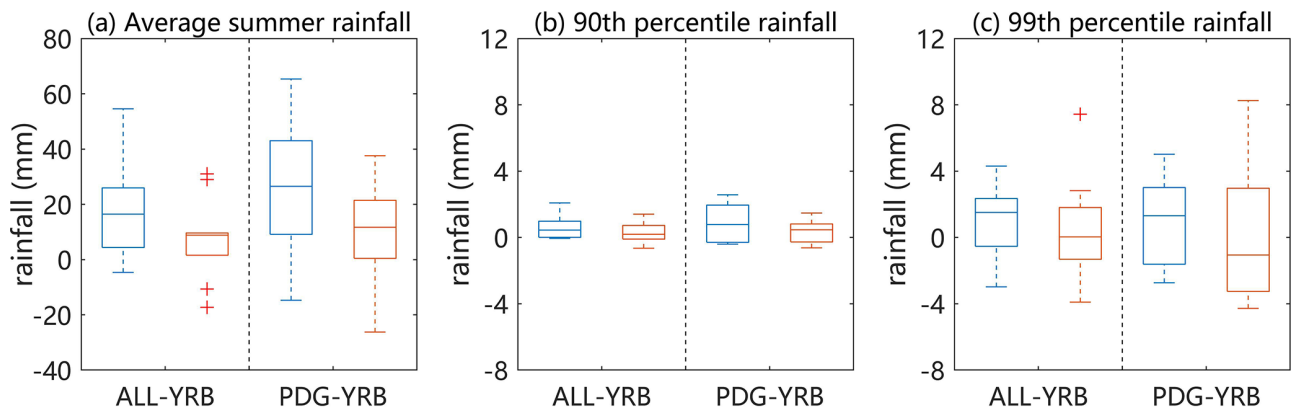

Figure 10. The changes in (a) average summer rainfall (mm), (b) 90 th percentile summer rainfall (mm $\mathrm{d}^{-1}$ ), and (c) 99th percentile summer rainfall $\left(\mathrm{mm} \mathrm{d}^{-1}\right.$ ) between the two hypothetical scenarios (20\% and $50 \%$ scenarios) and the 2010 scenario in the ALL-YRB and PDG-YRB area. The blue boxes represent the $20 \%$ scenario, while the red boxes represent the $50 \%$ scenario.
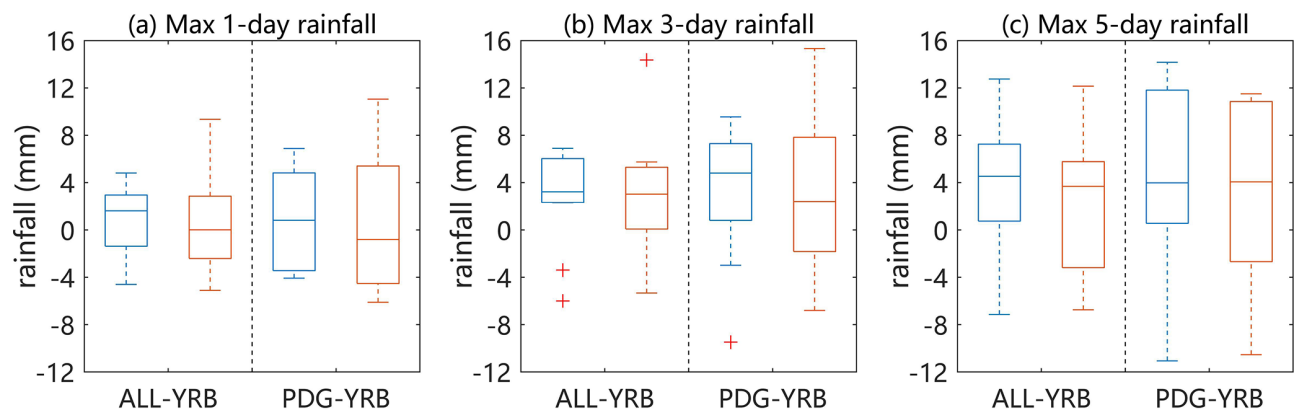

Figure 11. The changes in maximum (a) 1, (b) 3, and (c) $5 \mathrm{~d}$ rainfall between the two hypothesis scenarios (20\% and $50 \%$ scenarios) and the 2010 scenario in the ALL-YRB and PDG-YRB area. The blue boxes represent the $20 \%$ scenario, while the red boxes represent the $50 \%$ scenario.

ical reforestation scenarios and the 2010 scenario for both ALL-YRB and PDG-YRB. For rainfall for both ALL-YRB and PDG-YRB, all the relative changes for the $20 \%$ and $50 \%$ scenarios are positive. The relative changes in rainfall for the $20 \%$ scenario are more significant than those for the $50 \%$ scenario, except in June for ALL-YRB. Furthermore, the relative changes for PDG-YRB are more significant than those for ALL-YRB for all months in summer. The results indicate the following. (1) The reforestation, no matter for the $20 \%$ or $50 \%$ scenarios, increases summer rainfall. (2) Under the impact of the reforestation, the $20 \%$ scenario results in a more significant increase of summer rainfall than the $50 \%$ scenario. (3) The impacts of reforestation on average monthly rainfall during the summer period are more significant for populated areas.

\subsubsection{Changes in the latent heat flux, sensible heat flux, and planetary boundary layer height}

The changes in the LHF, SHF, and PBLH are investigated after analyzing the changes in rainfall under reforestation. Figure 13a and $b$ show the changes in LHF between the $20 \%$ scenario and the 2010 scenario and between the $50 \%$ scenario and the 2010 scenario, respectively. The spatial distributions of LHF changes for the $20 \%$ and $50 \%$ scenarios are similar. For example, the LHF increases in most places of the southeastern YRB and decreases in most places of the upstream and midstream for both scenarios. The most significant increases of LHF (up to $20 \mathrm{~W} \mathrm{~m}^{-2}$ ) are also mainly observed in the southeastern YRB for both scenarios. From the results of the significance test in Fig. 13a and b, it can be found that the increases of LHF were more significant than decreases after reforestation. The changes in SHF have similar spatial distribution for both the $20 \%$ and $50 \%$ scenarios (Fig. 13c and d). The SHF decreases in many places of the YRB, while the increases of SHF are mainly observed in the north YRB. The largest SHF decreases up to $-15 \mathrm{~W} \mathrm{~m}^{-2}$ are mainly seen in the southeastern YRB. However, areas with increased SHF are more for the $50 \%$ scenario than for the $20 \%$ scenario. Moreover, through a quantitative investigation in changes of LHF and SHF over the whole basin, it can be found that the basin-averaged summer daily LHF increases by 0.26 and $0.61 \mathrm{~W} \mathrm{~m}^{-2}$ for the $20 \%$ and $50 \%$ scenarios, respectively, while the basin-averaged summer daily SHF decreases by 0.54 and increases by $0.54 \mathrm{~W} \mathrm{~m}^{-2}$ for the $20 \%$ and $50 \%$ scenarios, respectively. Figure $13 \mathrm{e}$ and $\mathrm{f}$ show the changes in PBLH between the $20 \%$ scenario and the 2010 scenario and between the $50 \%$ scenario and the 2010 scenario, respectively. The spatial distributions of PBLH change are similar for both $20 \%$ and $50 \%$ scenar- 

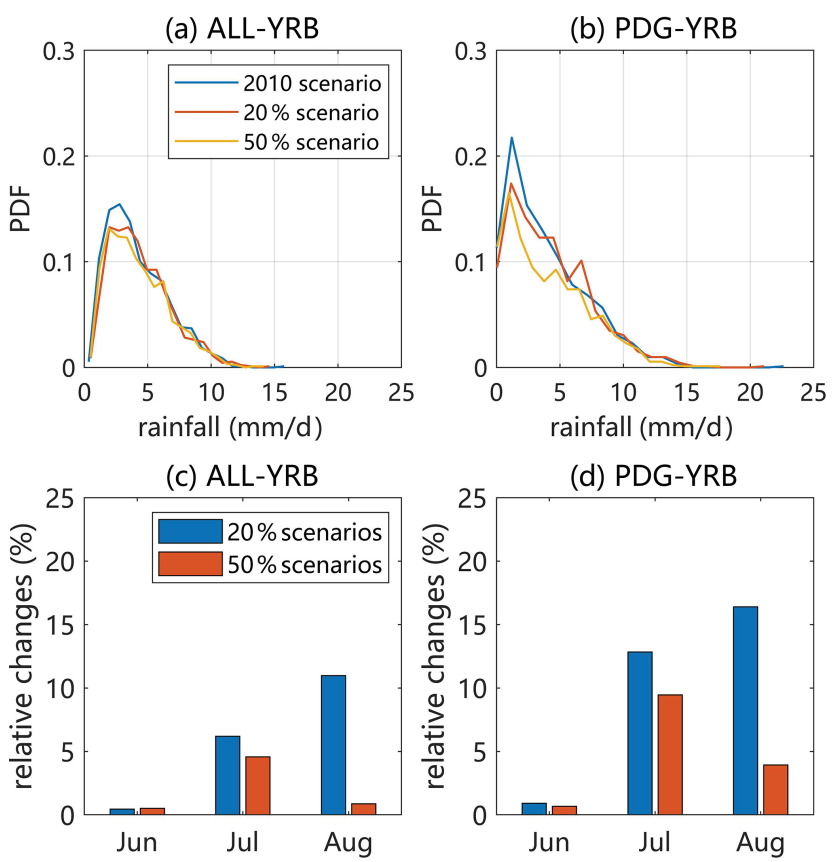

Figure 12. The probability distribution functions of summer rainfall in 2010, 20\%, and 50\% scenarios in (a) ALL-YRB and (b) PDGYRB. The changes in multiyear-averaged summer monthly rainfall between the two hypothetical scenarios (20\% and $50 \%$ scenarios) and the 2010 scenario in (c) ALL-YRB and (d) PDG-YRB.

ios. Nevertheless, there are more areas with PBLH increases of more than $30 \mathrm{~m}$ or decreases of more than $-30 \mathrm{~m}$ for the $50 \%$ scenario than for the $20 \%$ scenario.

The changes in SHF caused by reforestation can alter the thermodynamic variable PBLH. From Fig. 13, it can be seen that the changes in SHF and PBLH have a similar spatial pattern. When the SHF increases, it leads to increases in the PBLH, which will increase the possibility of cloud formation and finally enhance the intensity and frequency of extreme rainfall (Shem and Shepherd, 2009).

\subsubsection{Changes in the $2 \mathrm{~m}$ air temperature, relative humidity, and water vapor mixing ratio}

Changes in the $2 \mathrm{~m}$ air temperature, $2 \mathrm{~m}$ relative humidity, and $2 \mathrm{~m}$ water vapor mixing ratio under reforestation are also analyzed. Figure $14 \mathrm{a}$ and $\mathrm{b}$ present the average summer temperature changes between the $20 \%$ scenario and the 2010 scenario and between the $50 \%$ scenario and the 2010 scenario, respectively. For the $20 \%$ scenario, the average summer temperature decreases in most places of the YRB, while the decreases are mainly observed in the central YRB. In only a few small areas in the source region and the eastern part of the YRB does the temperature increase. For the 50\% scenario, areas with decreased average summer temperature are reduced compared with that for the $20 \%$ scenario. The maximum drop in the summer temperature is $-0.8^{\circ} \mathrm{C}$ for the $20 \%$ scenario and $-0.6{ }^{\circ} \mathrm{C}$ for the $50 \%$ scenario. Meanwhile, there are significant differences between the two scenarios in some regions. For example, in the north of the central YRB, the average summer temperature increases in the $50 \%$ scenario, while it decreases in the $20 \%$ scenario. Moreover, changes in surface skin temperature are also analyzed, and the results are almost the same as changes in $2 \mathrm{~m}$ air temperature (Fig. S5 in the Supplement).

Figure $14 \mathrm{c}$ and $\mathrm{d}$ present the changes in $2 \mathrm{~m}$ relative humidity between the $20 \%$ scenario and the 2010 scenario and between the $50 \%$ scenario and the 2010 scenario, respectively. From the figures, we can find that the relative humidity changes for these two hypothetical reforestation scenarios have different spatial distributions. For instance, for the $20 \%$ scenario, the relative humidity increases in most places of the YRB, with the most significant increases (up to $6 \%$ ) in the central YRB. When comparing Fig. 14c and d, it can be seen that more areas with increased relative humidity can be found in the $20 \%$ scenario than in the $50 \%$ scenario. Furthermore, the relative humidity decreases in the north of the central YRB in the $50 \%$ scenario, which is not observed in the $20 \%$ scenario. Figure $14 \mathrm{e}$ and $\mathrm{f}$ present the changes in the $2 \mathrm{~m}$ water vapor mixing ratio between the $20 \%$ scenario and 2010 scenario and between the $50 \%$ scenario and 2010 scenario, respectively. The results show that the water vapor mixing increased at $2 \mathrm{~m}$, especially for the $20 \%$ scenario. For the $50 \%$ scenario, there were more areas with a significant water vapor mixing ratio increase than areas with a significant water vapor mixing ratio decrease.

From the changes in the $2 \mathrm{~m}$ air temperature and $2 \mathrm{~m}$ relative humidity under reforestation, it can be seen that the $2 \mathrm{~m}$ relative humidity decreases where the $2 \mathrm{~m}$ air temperature increases. In addition, the water vapor mixing ratio in the atmosphere increases, which finally provides conditions for the increases of summer rainfall amount and extremes.

\section{Discussions}

Comparing the WRF modeling results with observation data, the summer rainfall from the WRF model tends to have positive biases in the northwestern YRB and negative biases in the southeastern YRB. The explanation is that on the one hand, the upstream of the YRB is a mountainous region, where only a few rainfall stations are located, as opposed to the many rainfall stations located in the valley, which may result in an underestimation of the rainfall. On the other hand, the resolution of topography used in the model of $15 \mathrm{~km}$ probably impacts the performance of rainfall. Previous studies found that the drag forces of the mesoscale $(3-10 \mathrm{~km})$ and microscale $(<3 \mathrm{~km})$ orography would prevent the moisture flux from being taken to the high-altitude complex terrain region (Wang et al., 2020). However, in our studies, the horizontal resolution of the inner domain is $15 \mathrm{~km}$, which cannot take the mesoscale and microscale orography into account. 
(a) Latent heat flux $\left(\mathrm{W} \mathrm{m}^{-2}\right)$

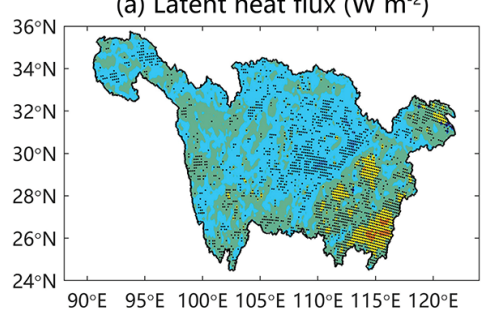

(b) Latent heat flux $\left(\mathrm{W} \mathrm{m}^{-2}\right)$

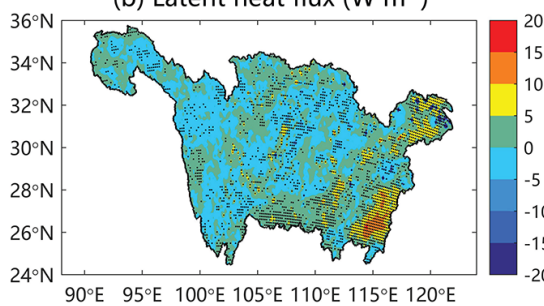

$20 \%$ scenario

(c) Sensible heat flux $\left(\mathrm{W} \mathrm{m}^{-2}\right)$

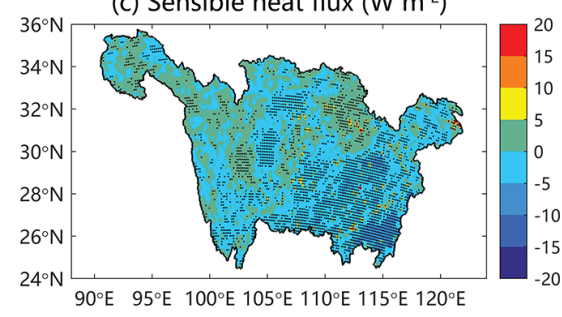

$50 \%$ scenario

(d) Sensible heat flux $\left(\mathrm{W} \mathrm{m}^{-2}\right)$

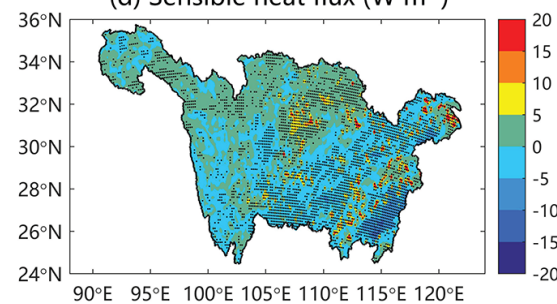

(e) PBLH (m)

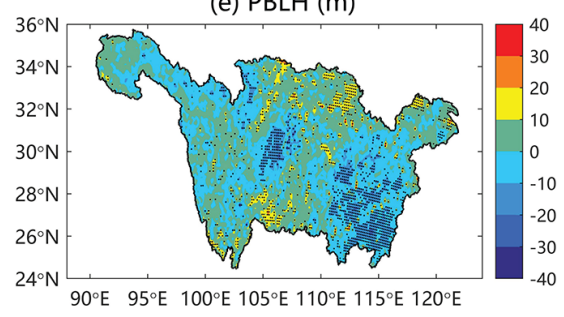

(f) PBLH (m)

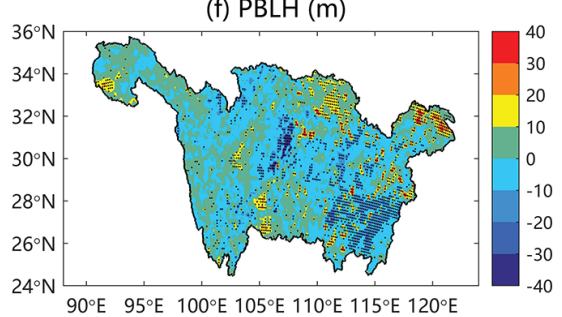

Figure 13. The changes in (a, b) latent heat flux (LHF, $\left.\mathrm{W} \mathrm{m}^{-2}\right),(\mathbf{c}, \mathbf{d})$ sensible heat flux $\left(\mathrm{SHF}, \mathrm{W} \mathrm{m}^{-2}\right.$ ), and (e, f) planetary boundary layer height (PBLH, m) between the $20 \%$ scenario and the 2010 scenario and between the $50 \%$ scenario and the 2010 scenario. The stippled regions show statistical significance of the changes identified by the $t$ test at a $5 \%$ significance level.

(a) $2 \mathrm{~m}$ air temperature $\left({ }^{\circ} \mathrm{C}\right)$

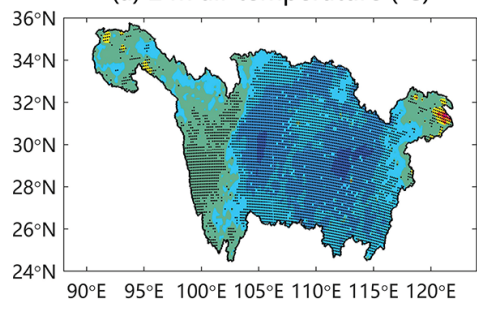

(b) $2 \mathrm{~m}$ air temperature $\left({ }^{\circ} \mathrm{C}\right)$

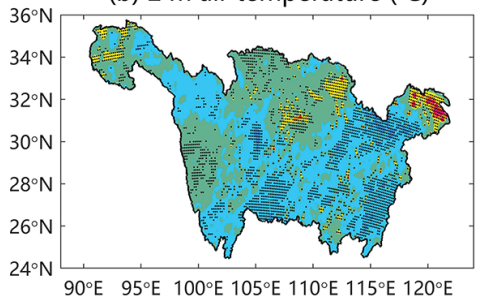

$20 \%$ scenario

(c) $2 \mathrm{~m}$ relative humidity (\%)

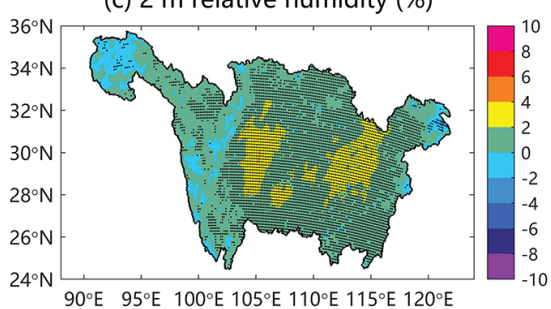

$\mathbf{5 0} \%$ scenario

(d) $2 \mathrm{~m}$ relative humidity (\%)

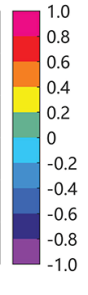

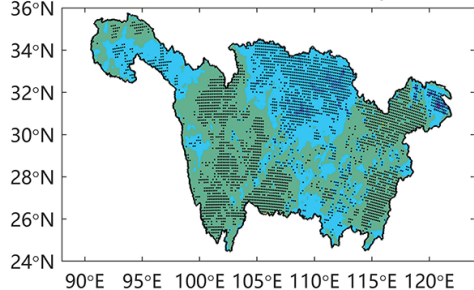

(e) $2 \mathrm{~m}$ water vapor mixing ratio $(\mathrm{g} / \mathrm{kg})$
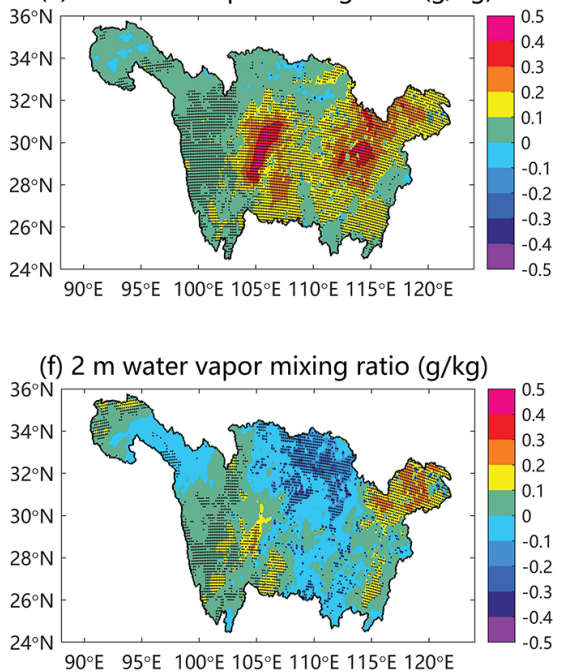

Figure 14. The changes in (a, b) $2 \mathrm{~m}$ air temperature $\left({ }^{\circ} \mathrm{C}\right),(\mathbf{c}, \mathbf{d}) 2 \mathrm{~m}$ relative humidity $(\%)$, and $(\mathbf{e}, \mathbf{f}) 2 \mathrm{~m}$ water vapor mixing ratio $(\mathrm{g} \mathrm{kg}-1)$ between the $20 \%$ scenario and the 2010 scenario and between the $50 \%$ scenario and the 2010 scenario. The stippled regions show statistical significance of the changes identified by the $t$ test at a $5 \%$ significance level.

Thus, the drag forces of the terrain are diminished, and more moisture is taken from the low-altitude region (i.e., the southeastern YRB) to the high-altitude region (i.e., the upstream of the YRB), which finally means that the simulated rainfall tends to have positive biases in the high-elevation area over the upstream of the YRB and negative biases in the lowelevation area over the southeastern YRB. We acknowledge that there are uncertainties from the bias of WRF modeling in the study. However, the WRF model can still be used to investigate the impacts of LULCC and reforestation on summer rainfall. The only difference in the initial conditions used to force the WRF model for the four scenarios is the land cover. Thus, the changes in summer rainfall between different scenarios can be considered the result of LULCC.

The changes in average summer rainfall show a sizable spatial heterogeneity between the 1990 and 2010 scenarios, while the 99th percentile summer daily rainfall shows significant increases in most places of the midstream and down- 
stream of the YRB. The land use changes from 1990 to 2010 involve not only the increase of forests, but also the change of other land uses. Table 1 shows that from 1990 to 2010, the area of cropland decreased from $29.15 \%$ to $28.48 \%$ for the whole basin, the area of forest increased from $42.82 \%$ to $43.60 \%$, the area of grassland decreased slightly from $23.50 \%$ to $23.13 \%$, the area of water and wetland increased slightly from $1.65 \%$ to $1.79 \%$, the area of urban increased from $0.19 \%$ to $0.86 \%$, and the unused land decreased from $2.69 \%$ to $2.14 \%$. Therefore, although the forests increased between 1990 and 2010, the rainfall decreased with the joint impacts of all other land use changes. Furthermore, the main LULCC in the midstream and downstream of the YRB between the 1990 and 2010 scenarios is the rapid expansion of the urban area. Therefore, it can be inferred that urbanization may increase the intensity of 99th percentile summer daily rainfall at a local scale. Similar results can be found in other studies. For example, Wang et al. (2015) found that extreme rainfall events had a strong positive spatial correlation with the urban extent. Zhang et al. (2018) also found that urbanization led to an amplification of the total rainfall, along with a shift in the location of the maximum rainfall, and further increased the intensity and frequency of extreme flooding events. However, the basin-averaged results show that both the average summer rainfall and extreme summer rainfall decrease for the 2010 scenario compared with the 1990 scenario.

The rainfall changes between the two hypothetical reforestation scenarios (20\% and $50 \%$ scenarios) and the 2010 scenario show that transforming cropland to forest increases summer rainfall. However, transforming different proportions of cropland to forest has different impacts on local rainfall. With a transformation proportion of cropland to forest increase from $20 \%$ to $50 \%$, the summer rainfall increases less conversely. To better explain this result, the changes in the water vapor mixing ratio at $2 \mathrm{~m}$ (Fig. 14), upward moisture flux at the surface (Fig. S6 in the Supplement), and wind at $10 \mathrm{~m}$ (Fig. S7 in the Supplement) are further analyzed. It can be found that the number of grids showing increased upward moisture flux in the $50 \%$ scenario slightly exceeds that in the $20 \%$ scenario. In contrast, the $2 \mathrm{~m}$ water vapor mixing ratio increases over almost the whole basin in the $20 \%$ scenario, while it shows significant decreases in the midstream of the basin in the $50 \%$ scenario. From the surface level to the $2 \mathrm{~m}$ level, the moisture stays increased in the $20 \%$ scenario, while it decreases in the $50 \%$ scenario. This suggests that the distribution of moisture may be changed by the horizontal transportation processes. Furthermore, Fig. S7 shows that the $10 \mathrm{~m}$ wind decreases in most places of the Yangtze River basin for both scenarios, which is as expected because reforestation increases surface roughness. However, the $10 \mathrm{~m}$ wind increases around the reforested areas, accelerating the moisture export from the forest. It is worth noting that areas with an increase in $10 \mathrm{~m}$ wind are more expansive for the $50 \%$ scenario than for the $20 \%$ scenario, which means that more moisture is transported from the forest to other places for the $50 \%$ scenario. In addition, from the changes in wind direction shown in Fig. S7, it is seen that moisture exported from the forest is transported towards the southern regions and finally flows out the Yangtze River basin. The above analyses further prove that the differences between the $20 \%$ and $50 \%$ reforestation scenarios are mainly caused by the changes of horizontal wind. Moreover, Yu et al. (2020) found that vegetation greening reduced rainfall in some regions in southern China, which may be caused by the East Asian monsoon, as the East Asian monsoon significantly influences the summer rainfall patterns in China (Ding et al., 2007). Furthermore, comparing the simulation results from the whole YRB with the results from grids where the population density is greater than 100 per $\mathrm{km}^{2}$, it can be seen that the impacts of LULCC on summer rainfall are more significant for populated areas, which means that reforestation will have significant impacts on human lives.

Although a comprehensive assessment of the impacts of LULCC on summer rainfall amount and extremes was conducted in this study, some issues remained. For example, only one regional climate model (i.e., the WRF model) was used in this study, although it has been widely used in China (Huang et al., 2020; Azmat et al., 2020). Some previous studies indicated that results from a single RCM (regional climate model) had a significant uncertainty since RCMs could perform differently in the same region (Davin et al., 2020; Zhang et al., 2017). In this case, it is worth looking at the impacts of LULCC on summer rainfall and extremes based on an ensemble of multiple RCMs in future research. We are also aware that convective parameterizations differ significantly in their treatment of the cloud updrafts and downdrafts and mass-flux closure and triggering, often assuming that one is averaging over both cloud updrafts and the subsiding environment. As a result, all these schemes are better at predicting the area-average rainfall (Clark et al., 2016). Additionally, the cumulus parameterizations also introduce uncertainties to the model results (Liu et al., 2016). In addition, regarding the WRF spatial resolution impacts, we used $15 \mathrm{~km}$ in the study regarding a large nested domain, focusing on the Yangtze River basin with a total area of $\sim 1.8 \times 10^{6} \mathrm{~km}^{2}$. The modeling resolution in the study was comparable with other studies that investigate the impacts of land use and cover changes over a large region (e.g., Zhang et al., 2017, 2021; Zha et al., 2019). However, we acknowledged that higher model resolution of WRF simulation, e.g., convection-permitting scale, may better represent rainfall processes and the land surface (Knist et al., 2020; Kurkute et al., 2020).

Moreover, there were 32 eta levels of the model, and the top was at $50 \mathrm{hPa}$. We acknowledge that we did not test whether there were enough layers near the bottom to trust the surface values. However, many relevant studies used similar or fewer vertical levels to study the changes of these surface variables (e.g., Hu et al., 2015; Yu et al., 2020). Moreover, 
Gallus et al. (2009) found that doubling the number of vertical levels from 31 to 62 did not result in a consistent improvement in the rainfall forecasts. The skill might not be improved much by refining the number of levels, although we acknowledge that the finding from Gallus's study may be different as it is in a different study area. On the other hand, adding the number of levels requires more computing resources and running time, which will limit what we can achieve in the study regarding it, since it is already quite challenging to complete around 40 years of WRF simulations with such a large nested domain. Furthermore, we did not use an urban scheme in the WRF modeling in the study. However, the urban area was only $0.19 \%$ of the total area in 1990 and increased to be $0.86 \%$ in 2010 . In this case, the impact of urbanization can be ignored in the study, considering the increased urban area was only around $0.67 \%$ of the total area of the YRB from 1990 to 2010.

Furthermore, the random sampling method was used to produce the two hypothetical reforestation scenarios in this study. Thus, the grids where the cropland was changed to be forest tended to be distributed evenly among the croplands in the YRB. However, the reforestation process usually happened in specific areas that were relative to local policy. It was challenging to gather the related policies from multiple local governments over such a large basin. It could also be noticed that the crops were mainly located in specific areas such as the Sichuan Basin and the midstream and downstream of the YRB. Although we randomly chose the crop grids, the restoration grids concentrated on these specific areas, similar to the actual reforestation processes. Despite these points, this study could still provide insight into what would happen to summer rainfall under reforestation.

\section{Conclusions}

In this study, analysis based on the WRF model simulations was used to research the impacts of LULCC and reforestation on summer rainfall amount and extremes in the YRB. Two observed scenarios (1990 and 2010 scenarios) were chosen to compare and investigate the changes in summer rainfall under the impacts of LULCC during the last decades. In addition, two hypothetical reforestation scenarios $(20 \%$ and $50 \%$ scenarios) produced based on the 2010 scenario were used to test the sensitivity of summer rainfall to reforestation. The changes in summer rainfall between different scenarios were analyzed, and the potential mechanisms were discussed. The main conclusions are outlined below:

1. LULCC largely influenced summer rainfall amount and extremes during 1990-2010 in the YRB. The LULCC between the 1990 and 2010 scenarios decreases average summer rainfall. Although the extreme summer daily rainfall increases up to $50 \mathrm{~mm}$ in some places of the midstream and downstream, the overall pattern is a decrease for the whole basin.
2. Reforestation can affect heat flux, air temperature, relative humidity, and PBLH in the YRB, leading to more water vapor mixing in the atmosphere, which provides conditions for the increase of summer rainfall amount and extremes. Moreover, the effects of reforestation are more pronounced in populated areas than over the whole basin.

3. Although reforestation increases summer rainfall both in the total amount and extremes, differences exist in the scenarios with different reforestation proportions of $20 \%$ and $50 \%$. Specifically, with a transformation proportion of cropland to forest increase from $20 \%$ to $50 \%$, the summer rainfall increases less conversely. By analyzing the changes in water vapor mixing ratio, upward moisture flux, and $10 \mathrm{~m}$ wind, it is suggested that this result may be caused by the horizontal transportation processes of moisture.

Code availability. WRF code can be downloaded from https:// github.com/wrf-model/WRF (Skamarock et al., 2008).

Data availability. ERA Interim data are available through the ECMWF servers at https://apps.ecmwf.int/datasets/data/ interim-full-daily/ (Dee et al., 2011).

The observed rainfall and temperature data are available at https://data.tpdc.ac.cn/zh-hans/data/ 52c77e9c-df4a-4e27-8e97-d363fdfce10a/ (National Meteorological Information Center, 2019).

ERA5 data are available on the Copernicus Climate Change Service (C3S) Climate Data Store at https://cds.climate.copernicus. eu/cdsapp\#!/dataset/reanalysis-era5-single-levels?tab=form (Hersbach and Dee, 2016).

The 2010 Grid Population Dataset of China can be found at http: //www.geodoi.ac.cn/weben/doi.aspx?Id=131 (Fu et al., 2014).

Author contributions. JC, LL, and WL designed the overall study. JC and HC collected the data. WL and LL developed the model code and performed the simulations, with some contributions from QL. WL, JC, and LL contributed to the interpretation of results. WL wrote the paper, and JC and LL revised the paper.

Competing interests. The authors declare that they have no conflict of interest.

Disclaimer. Publisher's note: Copernicus Publications remains neutral with regard to jurisdictional claims in published maps and institutional affiliations.

Acknowledgements. This work has been partially supported by the Hubei Provincial Natural Science Foundation of China (grant no. 
2020CFA100), the National Natural Science Foundation of China (grant nos. 52079093 and 51779176), the Overseas Expertise Introduction Project for Discipline Innovation (111 Project), funded by the Ministry of Education and State Administration of Foreign Experts Affairs P.R. China (grant no. B18037), and the Center for Climate Dynamics (SKD) through the Bjerknes Centre for Climate Research (CHEX and 100878-FTI). We thank Priscilla Mooney (NORCE) for providing her suggestions in the early stages of analysis. The numerical calculations in this paper were done on the supercomputing system in the Supercomputing Center of Wuhan University.

Financial support. This research has been partially supported by the Hubei Provincial Natural Science Foundation of China (grant no. 2020CFA100), the National Natural Science Foundation of China (grant nos. 52079093 and 51779176), the Overseas Expertise Introduction Project for Discipline Innovation (111 Project), funded by the Ministry of Education and State Administration of Foreign Experts Affairs P.R. China (grant no. B18037), and the Center for Climate Dynamics (SKD) through the Bjerknes Centre for Climate Research (CHEX and 100878-FTI).

Review statement. This paper was edited by Nadav Peleg and reviewed by Emma Daniels, Yan Li, and one anonymous referee.

\section{References}

Al-Falahi, A. H., Saddique, N., Spank, U., Gebrechorkos, S. H., and Bernhofer, C.: Evaluation the Performance of Several Gridded Precipitation Products over the Highland Region of Yemen for Water Resources Management, Remote Sens.-Basel, 12, 2984, https://doi.org/10.3390/rs12182984, 2020.

Azmat, M., Wahab, A., Huggel, C., Qamar, M. U., Hussain, E., Ahmad, S., and Waheed, A.: Climatic and hydrological projections to changing climate under CORDEXSouth Asia experiments over the Karakoram-HindukushHimalayan water towers, Sci. Total Environ., 703, 135010, https://doi.org/10.1016/j.scitotenv.2019.135010, 2020.

Bennett, M. T., Mehta, A., and Xu, J.: Incomplete property rights, exposure to markets and the provision of environmental services in China, China Econ. Rev., 22, 485-498, https://doi.org/10.1016/j.chieco.2010.12.002, 2011.

Berrisford, P., Dee, D. P., Poli, P., Brugge, R., Mark, F., Manuel, F., Kållberg, P. W., Kobayashi, S., Uppala, S., and Adrian, S.: The ERA-Interim archive Version 2.0, ECMWF, Shinfield Park, Reading, 2011.

Chen, S.-H., and Sun, W.-Y.: A One-dimensional Time Dependent Cloud Model, J. Meteorol. Soc. Jpn. Ser. II, 80, 99-118, https://doi.org/10.2151/jmsj.80.99, 2002.

Chen, Y., Zhang, A., Zhang, Y., Cui, C., Wan, R., Wang, B., and Fu, Y.: A Heavy Precipitation Event in the Yangtze River Basin Led by an Eastward Moving Tibetan Plateau Cloud System in the Summer of 2016, J. Geophys. Res.-Atmos., 125, e2020JD032429, https://doi.org/10.1029/2020jd032429, 2020.

Clark, P., Roberts, N., Lean, H., Ballard, S. P., and CharltonPerez, C.: Convection-permitting models: a step-change in rainfall forecasting, Meteorol. Appl., 23, 165-181, https://doi.org/10.1002/met.1538, 2016.

Cui, X., Liu, S., and Wei, X.: Impacts of forest changes on hydrology: a case study of large watersheds in the upper reaches of Minjiang River watershed in China, Hydrol. Earth Syst. Sci., 16, 4279-4290, https://doi.org/10.5194/hess-16-4279-2012, 2012.

Davin, E. L., Rechid, D., Breil, M., Cardoso, R. M., Coppola, E., Hoffmann, P., Jach, L. L., Katragkou, E., de Noblet-Ducoudré, N., Radtke, K., Raffa, M., Soares, P. M. M., Sofiadis, G., Strada, S., Strandberg, G., Tölle, M. H., Warrach-Sagi, K., and Wulfmeyer, V.: Biogeophysical impacts of forestation in Europe: first results from the LUCAS (Land Use and Climate Across Scales) regional climate model intercomparison, Earth Syst. Dynam., 11, 183-200, https://doi.org/10.5194/esd-11-1832020, 2020.

Dee, D. P., Uppala, S. M., Simmons, A. J., Berrisford, P., Poli, P., Kobayashi, S., Andrae, U., Balmaseda, M. A., Balsamo, G., Bauer, D. P., and Bechtold, P.: The ERAInterim reanalysis: Configuration and performance of the data assimilation system, Q. J. Roy. Meteor. Soc., 137, 553597, https://doi.org/10.1002/qj.828, (data available at: https: //apps.ecmwf.int/datasets/data/interim-full-daily/, last access: 27 March 2021), 2011.

Ding, Y., Ren, G., Zhao, Z., Xu, Y., Luo, Y., Li, Q., and Zhang, J.: Detection, causes and projection of climate change over China: An overview of recent progress, Adv. Atmos. Sci., 24, 954-971, https://doi.org/10.1007/s00376-007-0954-4, 2007.

Dudhia, J.: Numerical Study of Convection Observed during the Winter Monsoon Experiment Using a Mesoscale Two-Dimensional Model, J. Atmos. Sci., 46, 3077-3107, https://doi.org/10.1175/15200469(1989)046<3077:NSOCOD>2.0.CO;2, 1988.

Fang, J., Tang, Y., and Son, Y.: Why are East Asian ecosystems important for carbon cycle research?, Sci. China Life Sci., 53, 753-756, https://doi.org/10.1007/s11427-010-4032-2, 2010.

Feng, J.-M., Wang, Y.-L., Ma, Z.-G., and Liu, Y.-H.: Simulating the Regional Impacts of Urbanization and Anthropogenic Heat Release on Climate across China, J. Climate, 25, 7187-7203, https://doi.org/10.1175/JCLI-D-11-00333.1, 2012.

Feng, Y., Li, H., Tong, X., Chen, L., and Liu, Y.: Projection of land surface temperature considering the effects of future land change in the Taihu Lake Basin of China, Global Planet. Change, 167, 24-34, https://doi.org/10.1016/j.gloplacha.2018.05.007, 2018.

Fu, J., Jiang, D., and Huang, Y.: $1 \mathrm{~km}$ Grid Population Dataset of China, available at: http://www.geodoi.ac.cn/weben/doi.aspx? Id=131 (last access: 25 July 2021), 2014.

Gallus, W. A., Aligo, E. A., and Segal, M.: On the Impact of WRF Model Vertical Grid Resolution on Midwest Summer Rainfall Forecasts, Weather Forecast., 24, 575-594, https://doi.org/10.1175/2008waf2007101.1, 2009.

Gao, F., de Colstoun, E. B., Ma, R., Weng, Q., Masek, J. G., Chen, J., Pan, Y., and Song, C.: Mapping impervious surface expansion using medium-resolution satellite image time series: a case study in the Yangtze River Delta, China, Int. J. Remote Sens., 33, 7609-7628, https://doi.org/10.1080/01431161.2012.700424, 2012.

Gao, Q., Li, Y., Wan, Y., Qin, X., Jiangcun, W., and Liu, Y.: Dynamics of alpine grassland NPP and its response to cli- 
mate change in Northern Tibet, Climatic Change, 97, 515-528, https://doi.org/10.1007/s10584-009-9617-z, 2009.

Gao, Q.-Z., Wan, Y.-F., Xu, H.-M., Li, Y., Jiangcun, W.-Z., and Borjigidai, A.: Alpine grassland degradation index and its response to recent climate variability in Northern Tibet, China, Quatern. Int., 226, 143-150, https://doi.org/10.1016/j.quaint.2009.10.035, 2010.

Gleixner, S., Demissie, T., and Diro, G. T.: Did ERA5 Improve Temperature and Precipitation Reanalysis over East Africa?, Atmosphere, 11, 996, https://doi.org/10.3390/atmos11090996, 2020.

Grell, G. A. and Dévényi, D.: A generalized approach to parameterizing convection combining ensemble and data assimilation techniques, Geophys. Res. Lett., 29, 38-31-38-34, https://doi.org/10.1029/2002gl015311, 2002.

Hersbach, H. and Dee, D.: ERA5 reanalysis is in production, ECMWF Newsletter 147, ECMWF, Reading, UK, data available at: https://cds.climate.copernicus.eu/cdsapp\#!/dataset/ reanalysis-era5-single-levels?tab=form (last access: 20 July 2021), 2016.

Hong, S.-Y., Dudhia, J., and Chen, S.-H.: A Revised Approach to Ice Microphysical Processes for the Bulk Parameterization of Clouds and Precipitation, Mon. Weather Rev., 132, 103-120, https://doi.org/10.1175/15200493(2004)132<0103:ARATIM>2.0.CO;2, 2004.

Hong, S.-Y., Noh, Y., and Dudhia, J.: A New Vertical Diffusion Package with an Explicit Treatment of Entrainment Processes, Mon. Weather Rev., 134, 2318-2341, https://doi.org/10.1175/MWR3199.1, 2006.

Hu, Y., Zhang, X.-Z., Mao, R., Gong, D.-Y., Liu, H.-B., and Yang, J.: Modeled responses of summer climate to realistic land use/cover changes from the 1980s to the 2000s over eastern China, J. Geophys. Res.-Atmos., 120, 167-179, https://doi.org/10.1002/2014jd022288, 2015.

Huang, Y., Wang, Y., Xue, L., Wei, X., Zhang, L., and Li, H.: Comparison of three microphysics parameterization schemes in the WRF model for an extreme rainfall event in the coastal metropolitan City of Guangzhou, China, Atmos. Res., 240, 104939, https://doi.org/10.1016/j.atmosres.2020.104939, 2020.

Hurtt, G. C., Frolking, S., Fearon, M. G., Moore, B., Shevliakova, E., Malyshev, S., Pacala, S. W., and Houghton, R. A.: The underpinnings of land-use history: three centuries of global gridded land-use transitions, wood-harvest activity, and resulting secondary lands, Glob. Change Biol., 12, 1208-1229, https://doi.org/10.1111/j.1365-2486.2006.01150.x, 2006.

Hurtt, G. C., Chini, L. P., Frolking, S., Betts, R. A., Feddema, J., Fischer, G., Fisk, J. P., Hibbard, K., Houghton, R. A., Janetos, A., Jones, C. D., Kindermann, G., Kinoshita, T., Klein Goldewijk, K., Riahi, K., Shevliakova, E., Smith, S., Stehfest, E., Thomson, A., Thornton, P., van Vuuren, D. P., and Wang, Y. P.: Harmonization of land-use scenarios for the period 1500-2100: 600 years of global gridded annual land-use transitions, wood harvest, and resulting secondary lands, Climatic Change, 109, 117, https://doi.org/10.1007/s10584-011-0153-2, 2011.

Kain, J. S.: The Kain-Fritsch Convective Parameterization: An Update, J. Appl. Meteorol., 43, 170-181, https://doi.org/10.1175/15200450(2004)043<0170:TKCPAU>2.0.CO;2, 2004.
Knist, S., Goergen, K., and Simmer, C.: Evaluation and projected changes of precipitation statistics in convection-permitting WRF climate simulations over Central Europe, Clim. Dynam., 55, 325-341, https://doi.org/10.1007/s00382-018-4147-x, 2020.

Kurkute, S., Li, Z., Li, Y., and Huo, F.: Assessment and projection of the water budget over western Canada using convectionpermitting weather research and forecasting simulations, Hydrol. Earth Syst. Sci., 24, 3677-3697, https://doi.org/10.5194/hess-243677-2020, 2020.

Li, J., Chen, F., Zhang, G., Barlage, M., Gan, Y., Xin, Y., and Wang, C.: Impacts of Land Cover and Soil Texture Uncertainty on Land Model Simulations Over the Central Tibetan Plateau, J. Adv. Model. Earth Sy., 10, 2121-2146, https://doi.org/10.1029/2018ms001377, 2018.

Li, L., Gochis, D. J., Sobolowski, S., and Mesquita, M. D. S.: Evaluating the present annual water budget of a Himalayan headwater river basin using a high-resolution atmospherehydrology model, J. Geophys. Res.-Atmos., 122, 4786-4807, https://doi.org/10.1002/2016jd026279, 2017.

Li, S., Xu, M., and Sun, B.: Long-term hydrological response to reforestation in a large watershed in southeastern China, Hydrol. Process., 28, 5573-5582, https://doi.org/10.1002/hyp.10018, 2014.

Li, W., Chen, J., and Zhang, Z.: Forest quality-based assessment of the Returning Farmland to Forest Program at the community level in SW China, Forest Ecol. Manag., 461, 117938, https://doi.org/10.1016/j.foreco.2020.117938, 2020.

Lin, L., Gao, T., Luo, M., Ge, E., Yang, Y., Liu, Z., Zhao, Y., and Ning, G.: Contribution of urbanization to the changes in extreme climate events in urban agglomerations across China, Sci. Total Environ., 744, 140264, https://doi.org/10.1016/j.scitotenv.2020.140264, 2020.

Lin, Q., Chen, J., Li, W., Huang, K., Tan, X., and Chen, H.: Impacts of land use change on thermodynamic and dynamic changes of precipitation for the Yangtze River Basin, China, Int. J. Climatol., 41, 3598-3614, https://doi.org/10.1002/joc.7037, 2021.

Liu, C., Ikeda, K., Rasmussen, R., Barlage, M., Newman, A. J., Prein, A. F., Chen, F., Chen, L., Clark, M., Dai, A., Dudhia, J., Eidhammer, T., Gochis, D., Gutmann, E., Kurkute, S., Li, Y., Thompson, G., and Yates, D.: Continentalscale convection-permitting modeling of the current and future climate of North America, Clim. Dynam., 49, 71-95, https://doi.org/10.1007/s00382-016-3327-9, 2016.

Liu, J., Liu, M., Deng, X., Zhuang, D., Zhang, Z., and Luo, D.: The land use and land cover change database and its relative studies in China, J. Geogr. Sci., 12, 275-282, https://doi.org/10.1007/BF02837545, 2002.

Liu, J., Liu, M., Zhuang, D., Zhang, Z., and Deng, X.: Study on spatial pattern of land-use change in China during 1995-2000, Sci. China Ser. D, 46, 373-384, https://doi.org/10.1360/03yd9033, 2003.

Liu, J., Liu, M., Tian, H., Zhuang, D., Zhang, Z., Zhang, W., Tang, X., and Deng, X.: Spatial and temporal patterns of China's cropland during 1990-2000: An analysis based on Landsat TM data, Remote Sens. Environ., 98, 442-456, https://doi.org/10.1016/j.rse.2005.08.012, 2005.

Liu, J., Zhang, Z., Xu, X., Kuang, W., Zhou, W., Zhang, S., Li, R., Yan, C., Yu, D., Wu, S., and Jiang, N.: Spatial patterns and driving forces of land use change in China during the early 21 st cen- 
tury, J. Geogr. Sci., 20, 483-494, https://doi.org/10.1007/s11442010-0483-4, 2010.

Liu, J., Zhang, Q., and Hu, Y.: Regional differences of China's urban expansion from late 20th to early 21 st century based on remote sensing information, Chinese Geogr. Sci., 22, 1-14, https://doi.org/10.1007/s11769-012-0510-8, 2012.

Liu, Y., Zhang, X., Xia, D., You, J., Rong, Y., and Bakir, M.: Impacts of Land-Use and Climate Changes on Hydrologic Processes in the Qingyi River Watershed, China, J. Hydrol. Eng., 18, 1495-1512, https://doi.org/10.1061/(asce)he.19435584.0000485, 2013.

Maw, K. W. and Min, J.: Impacts of Microphysics Schemes and Topography on the Prediction of the Heavy Rainfall in Western Myanmar Associated with Tropical Cyclone ROANU (2016), Adv. Meteorol., 2017, https://doi.org/10.1155/2017/3252503, 2017.

Mlawer, E. J., Taubman, S. J., Brown, P. D., Iacono, M. J., and Clough, S. A.: Radiative transfer for inhomogeneous atmospheres: RRTM, a validated correlated-k model for the longwave, J. Geophys. Res.-Atmos., 102, 16663-16682, https://doi.org/10.1029/97JD00237, 1997.

Nanding, N., Chen, Y., Wu, H., Dong, B., Tian, F., Lott, F. C., Tett, S. F. B., Rico-Ramirez, M. A., Chen, Y., Huang, Z., Yan, Y., Li, D., Li, R., Wang, X., and Fan, X.: Anthropogenic Influences on 2019 July Precipitation Extremes Over the Mid-Lower Reaches of the Yangtze River, Frontiers in Environmental Science, 8, 603061, https://doi.org/10.3389/fenvs.2020.603061, 2020.

National Meteorological Information Center: Daily meteorological dataset of basic meteorological elements of China National Surface Weather Station (V3.0) (19512010), available at: https://data.tpdc.ac.cn/zh-hans/data/ 52c77e9c-df4a-4e27-8e97-d363fdfce10a/ (last access: 25 July 2021), 2019.

Niu, G.-Y., Yang, Z.-L., Mitchell, K. E., Chen, F., Ek, M. B., Barlage, M., Kumar, A., Manning, K., Niyogi, D., Rosero, E., Tewari, M., and Xia, Y.: The community Noah land surface model with multiparameterization options (Noah-MP): 1. Model description and evaluation with localscale measurements, J. Geophys. Res.-Atmos., 116, D12109, https://doi.org/10.1029/2010JD015139, 2011.

Pitman, A. J., de Noblet-Ducoudré, N., Avila, F. B., Alexander, L. V., Boisier, J.-P., Brovkin, V., Delire, C., Cruz, F., Donat, M. G., Gayler, V., van den Hurk, B., Reick, C., and Voldoire, A.: Effects of land cover change on temperature and rainfall extremes in multi-model ensemble simulations, Earth Syst. Dynam., 3, $213-$ 231, https://doi.org/10.5194/esd-3-213-2012, 2012.

Robbins, A. S. T., and Harrell, S.: Paradoxes and Challenges for China's Forests in the Reform Era, China Quart., 218, 381-403, https://doi.org/10.1017/S0305741014000344, 2014.

Shem, W. and Shepherd, M.: On the impact of urbanization on summertime thunderstorms in Atlanta: Two numerical model case studies, Atmos. Res., 92, 172-189, https://doi.org/10.1016/j.atmosres.2008.09.013, 2009.

Shen, S., Yue, P., and Fan, C.: Quantitative assessment of land use dynamic variation using remote sensing data and landscape pattern in the Yangtze River Delta, China, Sustain. Comput.-Infor., 23, 111-119, https://doi.org/10.1016/j.suscom.2019.07.006, 2019.
Skamarock, W. C., Klemp, J. B., Dudhia, J., Gill, D. O., Barker, D. M., Duda, M. G., Huang, X.-Y., Wang, W., and Powers, J. G.: The official repository for the Weather Research and Forecasting (WRF) model, available at: https://github.com/wrf-model/WRF (last access: 25 July 2021), 2008.

Sun, X., Li, C. a., Kuiper, K. F., Zhang, Z., Gao, J., and Wijbrans, J. R.: Human impact on erosion patterns and sediment transport in the Yangtze River, Global Planet. Change, 143, 88-99, https://doi.org/10.1016/j.gloplacha.2016.06.004, 2016.

Tarek, M., Brissette, F. P., and Arsenault, R.: Evaluation of the ERA5 reanalysis as a potential reference dataset for hydrological modelling over North America, Hydrol. Earth Syst. Sci., 24, 2527-2544, https://doi.org/10.5194/hess-24-2527-2020, 2020.

Trac, C. J., Schmidt, A. H., Harrell, S., and Hinckley, T. M.: Is the Returning Farmland to Forest Program a Success? Three Case Studies from Sichuan, Environmental practice, 15, 350366, https://doi.org/10.1017/S1466046613000355, 2013.

Wagner, S., Fersch, B., Yuan, F., Yu, Z., and Kunstmann, H.: Fully coupled atmospheric-hydrological modeling at regional and long-term scales: Development, application, and analysis of WRF-HMS, Water Resour. Res., 52, 3187-3211, https://doi.org/10.1002/2015WR018185, 2016.

Wang, D., Jiang, P., Wang, G., and Wang, D.: Urban extent enhances extreme precipitation over the Pearl River Delta, China, Atmos. Sci. Lett., 16, 310-317, https://doi.org/10.1002/as12.559, 2015.

Wang, Y., Rhoads, B. L., Wang, D., Wu, J., and Zhang, X.: Impacts of large dams on the complexity of suspended sediment dynamics in the Yangtze River, J. Hydrol., 558, 184-195, https://doi.org/10.1016/j.jhydrol.2018.01.027, 2018.

Wang, Y., Yang, K., Zhou, X., Chen, D., Lu, H., Ouyang, L., Chen, Y., Lazhu, and Wang, B.: Synergy of orographic drag parameterization and high resolution greatly reduces biases of WRFsimulated precipitation in central Himalaya, Clim. Dynam., 54, 1729-1740, https://doi.org/10.1007/s00382-019-05080-w, 2020.

Wen, Q. H., Zhang, X., Xu, Y., and Wang, B.: Detecting human influence on extreme temperatures in China, Geophys. Res. Lett., 40, 1171-1176, https://doi.org/10.1002/grl.50285, 2013.

Xue, H., Jin, Q., Yi, B., Mullendore, G. L., Zheng, X., and Jin, H.: Modulation of Soil Initial State on WRF Model Performance Over China, J. Geophys. Res.-Atmos., 122, 11278-11300, https://doi.org/10.1002/2017JD027023, 2017.

Yan, Y., Tang, J., Wang, S., Niu, X., and Le, W.: Uncertainty of land surface model and land use data on WRF model simulations over China, Clim. Dynam., https://doi.org/10.1007/s00382-02105778-w, 2021.

Yang, Z.-L., Niu, G.-Y., Mitchell, K. E., Chen, F., Ek, M. B., Barlage, M., Longuevergne, L., Manning, K., Niyogi, D., Tewari, M., and Xia, Y.: The community Noah land surface model with multiparameterization options (Noah-MP): 2. Evaluation over global river basins, J. Geophys. Res.-Atmos., 116, D12110, https://doi.org/10.1029/2010JD015140, 2011.

Yu, L., Liu, Y., Liu, T., and Yan, F.: Impact of recent vegetation greening on temperature and precipitation over China, Agr. Forest Meteorol., 295, 108197, https://doi.org/10.1016/j.agrformet.2020.108197, 2020.

Zha, J., Zhao, D., Wu, J., and Zhang, P.: Numerical simulation of the effects of land use and cover change on the near-surface wind speed over Eastern China, Clim. Dynam., 53, 1783-1803, https://doi.org/10.1007/s00382-019-04737-w, 2019. 
Zhang, D., Liu, X., and Bai, P.: Assessment of hydrological drought and its recovery time for eight tributaries of the Yangtze River (China) based on downscaled GRACE data, J. Hydrol., 568, 592603, https://doi.org/10.1016/j.jhydrol.2018.11.030, 2019.

Zhang, H., Wu, C., Chen, W., and Huang, G.: Effect of urban expansion on summer rainfall in the Pearl River Delta, South China, J. Hydrol., 568, 747-757, https://doi.org/10.1016/j.jhydrol.2018.11.036, 2019.

Zhang, J., Zhengjun, L., and Xiaoxia, S.: Changing landscape in the Three Gorges Reservoir Area of Yangtze River from 1977 to 2005: Land use/land cover, vegetation cover changes estimated using multi-source satellite data, Int. J. Appl. Earth Obs., 11, 403-412, https://doi.org/10.1016/j.jag.2009.07.004, 2009.

Zhang, W., Villarini, G., Vecchi, G. A., and Smith, J. A.: Urbanization exacerbated the rainfall and flooding caused by hurricane Harvey in Houston, Nature, 563, 384-388, https://doi.org/10.1038/s41586-018-0676-z, 2018.
Zhang, X., Xiong, Z., Zhang, X., Shi, Y., Liu, J., Shao, Q., and Yan, X.: Simulation of the climatic effects of land use/land cover changes in eastern China using multimodel ensembles, Global Planet. Change, 154, 1-9, https://doi.org/10.1016/j.gloplacha.2017.05.003, 2017.

Zhang, X., Chen, J., and Song, S.: Divergent impacts of land use/cover change on summer precipitation in eastern China from 1980 to 2000, Int. J. Climatol., 41, 2360-2374, https://doi.org/10.1002/joc.6963, 2021.

Zhang, Y., Song, C., Zhang, K., Cheng, X., Band, L. E., and Zhang, Q.: Effects of land use/land cover and climate changes on terrestrial net primary productivity in the Yangtze River Basin, China, from 2001 to 2010, J. Geophys. Res.-Biogeo., 119, 1092-1109, https://doi.org/10.1002/2014JG002616, 2014.

Zinda, J. A., Trac, C. J., Zhai, D., and Harrell, S.: Dual-function forests in the returning farmland to forest program and the flexibility of environmental policy in China, Geoforum, 78, 119-132, https://doi.org/10.1016/j.geoforum.2016.03.012, 2017. 